\title{
The Plausibility of Universal Health Care in the United States
}

\section{Richard Boudreau*}

Attorney at Law and Faculty, Bioethics Institute, Loyola Marymount University, CA, USA

*Corresponding author: Richard Boudreau, Attorney at Law and Faculty, Bioethics Institute, Loyola Marymount University, CA, USA, Tel: 310-822-6161; E-mail: drboudreau6@aol.com

Received date: February 04, 2017; Accepted date: March 23, 2017; Published date: March 24, 2017

Copyright: @ 2017 Boudreau R. This is an open-access article distributed under the terms of the Creative Commons Attribution License, which permits unrestricted use, distribution, and reproduction in any medium, provided the original author and source are credited.

\begin{abstract}
Though the United States is one of the wealthiest nations in the world, the disparities in income are only surpassed by the inequalities in access to health care. Because of the close tie between the health care crisis and the fiscal health of the country as a whole, proposals have been made to introduce universal health care, to adapt existing systems and to support efforts, including what has been deemed "ObamaCare" to move towards greater accountability in obtaining and maintaining health insurance for the millions of uninsured and underinsured. Though most countries in the developed world perceive health care as a basic human right, the United States has yet to determine a way of creating and funding a single-payer universal health care system that will address the inequalities that exist and provide a better option for preventative medicine, interventive medicine, and long-term care.

One of the central problems for this country is that our political process is divided ideologically and health care paradigms do not appear to address issues on both sides. While there is support for a national health program that would ensure access to the working poor, fiscal conservatives view this as a system that cannot be afforded and that would expand debt in an uncontrollable manner. In fact, there is a clear division between the patriarchal perspectives of the democrats and the growing Tea Party call for personal responsibility.

The following study considers the issue of health care in this country, including the current level of expenditure, the lack of access, comparable international efforts, and even state proposed changes that have shown some success in the implementation of universal health care. This study will focus on the way in which innovation and governance have struggled to determine workable paradigms for health care reform. The focus on a single-payer or universal health care system has not led to successful legislative change, and so elements of both arguments will be considered when addressing the best methods for improving access to care and affordability. A proposed plan will be introduced that will consider the best options for improving the following: 1 . Affordability; 2 . Access to care; 3 . Long-term viability; 4 . State and federal cooperation; 5 . Distribution of funding or services. The proposed plan will address these issues and present some plausible approaches.
\end{abstract}

Keywords: Health care; ObamaCare; Health insurance

\section{United States and Health Care}

Though the United States is one of the world's wealthiest nations, the current economic downturn has served to emphasize the gap between the wealthy and the average Americans. One of the strongest indicators of wealth in this country has become access to healthcare. While the wealthy are able to afford every luxurious health care service, from private rooms to elective surgeries, the average American cannot afford a basic level of preventative care.

\section{The Industry}

Health care is a multi-trillion dollar industry in the United States and includes providers, insurers and government regulators that dictate the pricing and processes involved in the allocation of health care resources. The following statistics reflect some of the challenges and issues with the health care industry in this country, especially in reference to the allocation of resources:

- In 2005, the U.S. spent $\$ 2$ trillion on health care, which is 16 percent of GDP and \$6,697 per person.
- Health care costs have grown on average 2.5 percentage points faster than U.S. gross domestic product since 1970.

- Almost half of health care spending is used to treat just 5 percent of the population.

- Prescription drug spending is 10 percent of total health spending, but contributes to14 percent of the growth in spending.

- While about 26 percent of the poor spent more than 10 percent of their income on health in 1996, the number increased to 33 percent by 2003.

- Many policy experts believe new technologies and the spread of existing ones account for a large portion of medical spending and its growth [1].

The current economic downturn and high unemployment rates have led to an even larger portion of the population falling into the category of the uninsured or underinsured, with a large portion of the working poor being unable to meet their basic health care needs.

While healthcare takes up a large slice of the economic "pie" in this country, it seems surprising that so many Americans go without essential services [1]. Figure 1 shows that health care costs are 
becoming an increasing problem, especially for low-income families. These families are spending an increasing share of their income on health care essentials, making health care the faster growing segment of the national economy consuming a large percentage of the average family's yearly income. In 1970, for example, health care costs were about $\$ 356$ per year on average. In 40 years, that amount grew to about $\$ 6,697$ per person, making the health care industry one of the leading industries in this country, taking in approximately $\$ 2$ trillion annually (Figure 1) [1]. Current projections indicate that health care spending will consume approximately than $1 / 5$ of the gross domestic product of this country by $2016[1]$.

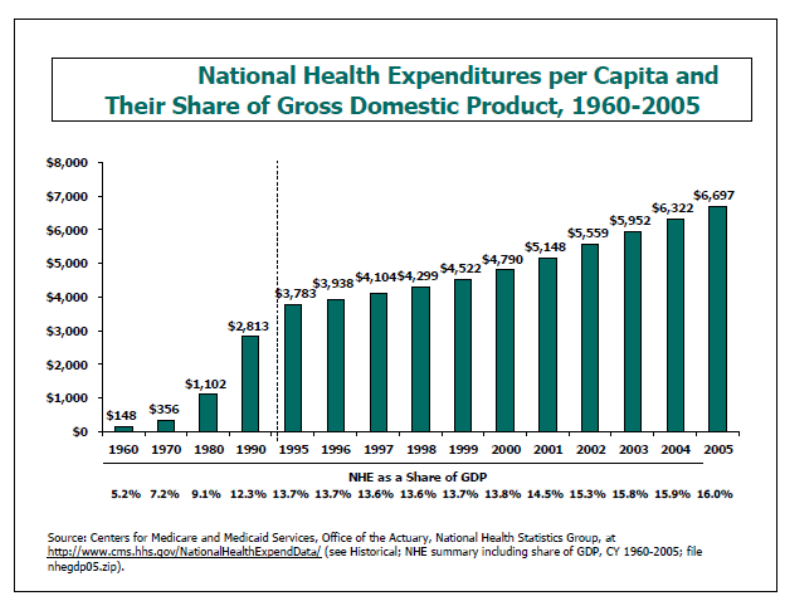

Figure 1: National Health Expenditures, Kaiser Family Foundation.

Bartlett and Steele [2] maintain that the American health care system is in critical condition, primarily the result of the creation a market-driven system for medical care and the increasing competition between health insurers driving costs upward. The creation of a health care system that is market driven creates a situation that is often oppositional: the process of providing services is costly, while the directive for market-driven companies is to make money. This viewpoint has been supported in major national movements towards implementing a national health system and in criticisms that maintain that the United States, though a country with one of the largest health care infrastructures, scores relatively low in terms of health care access and health outcomes for the masses.

Some believe that the issues with the American health care system relate to changes that occurred in the 1980s during the Reagan Administration [2]. Prior to that time, the health care system was based primarily in the existence of non-profit hospitals and health care facilities with a focus on providing services for illness prevention, emergent care and long-term care. Reorganization of the nation's hospitals under a free-market directive led to the creation of massive moneymaking health care conglomerates, uniting providers, facilities and insurance companies in an organizational structure directed towards profit. Because health services cost money and corporate health organizations are seeking to make money, patient care has suffered significantly as these companies have grown more powerful [2].

One of the central problems with allowing for a market-driven health care system is that there are fewer providers, hospitals and health care facilities than there is need. As a result, the cost of health care in the United States has skyrocketed. Rather than improving the product (health care) or improving the delivery system, the free market enterprise of health care has translated into a decline in health care conditions (because they can) and an increase in cost. Not only has this translated into poor health care in many urban centers, but has also created a system that makes illness prevention cost-prohibitive to the underinsured or uninsured.

Bartlett and Steele [2] maintain that the government has turned the issue over to the private organizations and asked them to sort out the profit-driven process through which health care has developed. As an increasing number of health care organizations and hospitals nationwide become moneymaking devices, the number of people served and the level of care decline. In these corporate monstrosities, health care is both a service and a commodity and so health care organizations have rejected a consumer focus and defined a focus on profit. Rather than creating a level of competitiveness, as suggested in the Reagan Administration's call for a focus on market-driven health care, the health care system is driven by such a great profit motive that it becomes easy to reject a compassionate response to the care needs of the many, and seek out ways of providing care for those who can pay the most for it.

\section{Access for all}

One of the central messages of modern health care reform initiatives is the belief that health care access should be a right of all people, not just a right for those who can afford it. Health care organizations, then, recognize the need for high turnover rates, quick turnaround times for hospital stays, limited focus on quality and questionable practices regarding the treatment of those unable to pay. Health insurance companies have also contributed to the overall problem. While individuals must pay hefty premiums for participation in these programs, the same companies do not always afford individuals the same level of consideration when they seek care. Insurance coverage does not always insure care and companies have made it difficult to obtain insurance without considerable expense. A large segment of the working class has turned to catastrophic coverage, coverage that only goes into effect after the payment of very large deductibles, a measure families use to protect their homes and economic stability, but not to ensure they have access to basic health care.

One of the misnomers about the market-driven health care system and the approach to meeting the needs of the masses is the idea that most people in the nation have access to health care through their employers, even if they are required to pay for a portion of that insurance, and so the uninsured and underinsured are a small segment of the population, including the very poor, the homeless, the unemployed and the disenfranchised. In truth, a large portion of the uninsured and underinsured in this country are working class families and children who do not qualify for public supported programs but who cannot afford health insurance premiums. Currently, more than 11.5 million children in this country do not have health insurance because their families cannot afford it, and only 40 percent of those families qualify for free or low cost Medicaid health insurance coverage [3].

Researchers have argued that since 2008, we have lost the battle to keep our nations families and children insured [3]. In fact, as poverty rates increase and median income in this nation decreases, the access to job-based health insurance and the continuation of health insurance coverage for the nation's workers and their families has also decreased [3]. Between 2007 and 2008, nearly 800,000 children lost their parent/ 
employer-sponsored health insurance, while the number of children requiring coverage under Medicare or CHIP [3] increased by nearly 1.7 million children [3]. Even so, the Center on Budget and Policy Priorities reports that 9.9 percent of the children in this country are uninsured. The Congressional Budget Office has projected that under existing policies, the number of uninsured citizens nationwide will continue to grow, and could top 54 million by 2019 [3].

Children who are uninsured or underinsured are much less likely to seek medical attention in a family practice setting, and often use the emergency room as their primary care provider. The lack of access to essential preventative care for almost 10 percent of the nation's youngest citizens is difficult to understand. Though few would deny that each child should have the right to health care access, the lack of a national health policy, one that allows for coverage for all Americans, keeps 1 in 10 children from receiving the care they need on a regular basis [3]. The underlying reason for this lack of attention to health care access for all is very simply an issue of economics. No one wants to pay the large bill of ensuring that every person in this country has access to adequate healthcare. The bill is daunting and ineffective policy makers find themselves talking about the cost, rather than the benefits. Data collected by the Center on Budget and Policy Priorities clearly demonstrates that the general public is paying for the lack of health insurance. In the same year that 800,000 children lost parent/ employer-paid health insurance, 1.7 million more children sought support through CHIP, creating a definable link between our lack of a health care policy and the increasing need for public resources to ensure health care access for children [3].

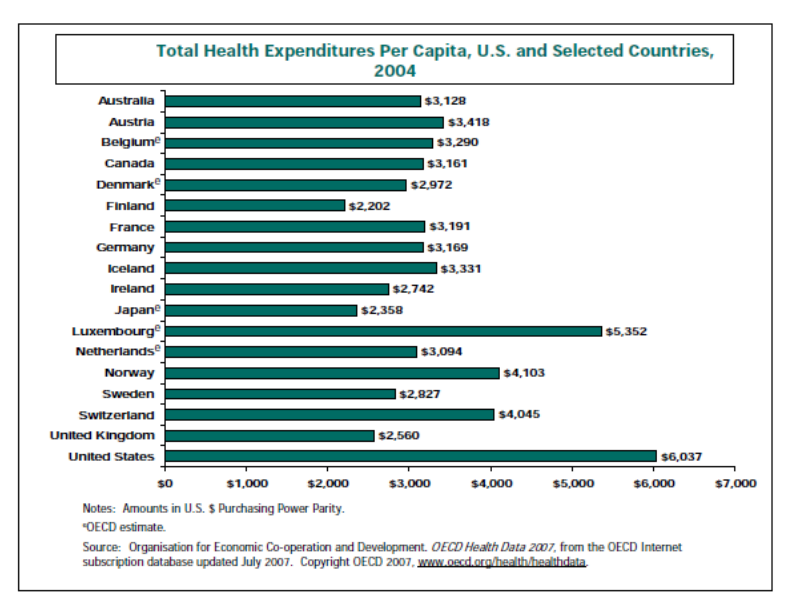

Figure 2: Per Capita Health Expenditure Comparison, Kaiser Family Foundation.

A healthcare policy that ensures access for all Americans should be an ethical directive in our country. Though we maintain a high quality of life and standards for economic and social growth, our lack of attention to healthcare is an ethical and political dilemma. In fact, the Centers for Disease Control and Prevention maintain that in 2009, the United States was ranked 30 out of 31 industrial countries in our infant mortality rate [4]. The only country with a higher infant mortality rate amongst industrial nations was Slovakia. Countries like Canada, the United Kingdom, Israel, Japan, Australia, and even Cuba all provided greater prenatal care and access to healthcare for pregnant mothers and their infants than the United States [4].
Another significant issue in the center of rhetoric around national health programs is that the United States cannot afford one. A comparison of other developed nations in the world underscores the belief that we cannot afford to NOT have one. Figure 2 identifies the per capita spending averages for countries worldwide and the United States is by far the highest spender in relation to health care costs. For a nation not meeting the health care demands of the masses, the cost exceeds countries like Canada, the UK, Germany and even Japan, all of which have national health care systems in place and high success rates in relation to preventative medicine [1].

\section{Preventative Care}

Though health professionals recognize the need for preventative services in health care as the basis for ensuring human health and wellbeing, there is little imperative for programming that would result in this kind of change. There are a variety of social, political and financial barriers to implementing health care paradigms that would support the provision of essential care to every American, including primary prevention services. These barriers include the lack of financial support for prevention strategies, problems with regulatory support for prevention methods, and the lack of access to healthcare in general. Prevention methods are only effective if individuals access care, and the problem of the lack of a national health system or other mechanism to ensure widespread access to preventative medicine has led to high mortality rates for treatable diseases in low-income populations.

The lack of access to healthcare relates directly to the inability to ensure primary prevention, even though most health professionals recognize that the prevention of health problems is a more costeffective approach to care than intervening after the fact. The expense of providing individual insurance coverage for a family can be astronomical and often cost-prohibitive. Most middle class families hoping to provide medical coverage for their families face high premium payments or large deductibles that can reduce the chances that they pursue adequate care. Though the cost of insurance is often less than the cost of health care services if paid on an individual basis, many families do not have the financial capacity to provide private coverage for their families from the onset.

The Kingdom model suggests that there is often a disconnect between political process, decision-making and the solutions that are proposed to major issues in the public sector. In the case of healthcare and the underinsured, the disconnect comes from the lack of a logical argument against adequate healthcare and the assertion that healthcare is too costly. In truth, the cost of healthcare for children with health problems is ten times that of the cost of preventative care for children who are adequately vaccinated and who receive attention and medical care at the first sign of illness. Unfortunately, the arguments held by policy makers suggests a kind of cyclical stream to the issue, that negates the more important view of how healthcare dollars that are not spent on preventative care result in greater long-term cost expenditures. The development of policy strategies to address the issue of the uninsured may reflect the nature of the problem.

Mark Robert Rank's [5] book One Nation, Underprivileged: Why American Poverty Affects Us All outlines a variety of arguments regarding the nature of poverty and reflects the need for a new method of addressing this social, economic and political problem. Rank identified the problem of poverty and the misconceptions regarding poverty when he first heard Charles Murray speak of the plight of the impoverished, maintaining the need to put a stop to the welfare system and address poverty for children by reinstating an orphanage system. 
Rank distributes the blame for American poverty, which has reached astronomical proportions in recent decades, to specific conditional elements and changing views of the welfare system. In understanding Rank's perspective and proposed solutions, it is necessary to understand the context of poverty and the approaches that others have taken to understanding its cause.

Rank's first section of his book, called The Nature of American Poverty, seeks to place poverty into a social and historical context. Rank does this because he believed that in order to determine change, it is necessary to direct the need for change to the specific conditions of the problem. Rank maintained: "Lasting change must begin with the realization that the status quo of widespread poverty within our borders is unwise, unjust and intolerable" [5]. Recognizing that poverty impacts our society as a whole, from the distribution of taxes to pay for poverty to the social and economic impacts of a large portion of the population unemployed, has led to his close scrutiny of the issue.

One of the central problems identified by Rank is that there are many different definitions of poverty. Poverty is often assessed in terms of income ranges, but Rank looks back at the historical context in which poverty has been defined, initially applying Adam Smith's definition from Wealth of Nations: "poverty as the lack of those necessities that the custom of the country renders it indecent for creditable people, even of the lowest order, to be without' [5]. This definition does not place poverty in a monetary context, but instead within an assessment of individuals getting what they need in order to function as a part of society. It is Rank's overall contention that the lack of resources for the poor lead to the lack of access to basic needs.

When Rank compiled his data following the 2002 census, there were 34.6 million Americans, or 12.1 percent of the population, who fell below the poverty line. Calculations of income levels at 1.25 and 1.50 of the poverty level led Rank to conclude that an additional 12.5 to 26.5 million Americans "live precariously close to the poverty line" [5]. Rank maintained that a growing number of children are living in poverty, while the annual earnings for young head of households with children have decreased over the past thirty years. In addition, changes in family structure have led to an increase in the number of women running families alone (p. 27). These reflections suggest that there is a need to consider the way in which poverty has progressed over the past thirty years and the essential factors that have led to the changing face of poverty.

There are a variety of other researchers who support Rank's social perspective on the issue of poverty. An article from the National Association of Social Workers (NASW) website discusses poverty and argues that it is about "much more than money alone" [6]. Poverty is the result of a number of factors including "political, social, and economic dynamics" [6]. For example, as the country has moved from a manufacturing economy to a service economy, "wages have been dramatically lowered for the average 'nonprofessional' worker" [6]. In addition to this, poverty affects a disproportionate number of women, a phenomenon that has been called the "feminization of poverty." This is one of the claims that can reasonably made about poverty-it affects women more than men, and this is reflected in Rank's text. The "feminization of poverty has been exacerbated by persistent disparities in salaries for men and women, as well as the disproportionate economic burden that single mothers face in raising children alone" [6]. That is, women have always earned less than men, even when they are doing the same jobs, a gap that has never been bridged. The fact that women do not make what they're worth, coupled with the fact that when a family breaks up it's the woman who usually has to care for the children, lead inevitably to the fact that when live in poverty in greater numbers than men.

Contrary to popular belief, the largest percentage of the population (a full 2/3) of impoverished Americans is white [5]. This corresponds with the claims made by other researchers, including Blank [7], who argued that the media represents the poor as being minorities, dangerous and living only in poor urban areas riddled with crime. Blank [7] argues that this assumption is incorrect and identifies three reasons why Americans continue to believe it. First, the media is choosy in what they report, picking sensational stories and ignoring those that are more reassuring [7]. Second, movies and TV are full of violent acts and lead to the presumption that real life is as dangerous as that on the screen and that poverty reflects criminality [7]. Finally, there is the question of sensationalism: paying a great deal of attention to the few "troublemakers" and ignoring the vast majority of people who do not get into trouble, but live below the poverty level [7]. Taken together, these factors lead to the assumption that the inner city is a violent and dangerous place and by extension, so are the poor people who live there. The evidence to support the idea that poor people are dangerous or criminals or evading work is deeply rooted in misconceptions.

Rank also maintained that the breadth of the problem in comparison to poverty in other developed nations is often underestimated. Of developed nations, the United States ranks first in the overall population living below $50 \%$ of the median income, and second only to the United Kingdom in overall population living below the United States poverty line [5]. This assertion underscores the problematic nature of contentions that the United States poverty is better than in other countries.

Rank argued, then, that poverty is actually a part of the structural failings of the country as a whole, an argument that takes some of the responsibility for poverty out of the hands of the poor. In his third chapter, Rank maintained the importance of recognizing how poverty came about. "The argument in this chapter is that such an emphasis is misplaced and misdirected. By focusing on individual attributes as the cause of poverty, we have largely missed the underlying dynamic of American impoverishment" [5]. Specifically, Rank explored the research that has been conducted and identified a number of studies that underscore the structure issues that result in poverty.

Rank [5] argued that the major factor that has led to poverty in the United States is a "failure of the economic structure to provide sufficient opportunities for all who are participating in the system. The labor market simply does not provide enough decent-paying jobs for all who need them". The three major inadequacies include: the lack of adequately paying jobs, the ineffectiveness of the welfare system, and the emerging belief that most Americans will experience poverty at some point in their lives.

Rank [5] recognized that many people try to ignore the issue of poverty, placing blame for poverty on the laziness of the individuals and rejecting the belief that poverty is a social, economic and political problem. Like Charles Murray, many believe that women who become pregnant repeatedly while in the welfare system comprise the largest portion of those collecting aid, and that efforts should be made to quell this kind of activity, including methods to reduce the incentives for continuing welfare.

Even those who want to get out of poverty often find it difficult and find that there is little political support for their plight. The underlying reason for this is that those who dictate social welfare for the poor 
rarely experience it firsthand. At the same time, the poor do not represent a highly vocal constituency. "Impoverishment significantly impacts the poor's ability to fully participate in the democratic process".

Rank argued, then, that in order for people to be effective members of society and active participants in citizenship, they must feel that they are a part of a system that can address their needs. Rank called for a greater focus on methods for change that are linked to the citizenship of those in power. "In many ways I argue that we must live up to the expression 'I am my brother's keeper.' The ability to do so is the finest sense of what it means to be a human" [5].

The fundamentals for change reflect the need to address how individuals who are not poor respond to those who are. Close scrutiny of the demographic traits of the poor, including the assessment of poverty as a growing part of the problem of familial dissolution, is just one aspect of the development of methods for change [8]. There is a need to reduce the social and political distance between the "haves" and the "have-nots" in order to address the way in which poverty is viewed. Rather than considering the poor a separate group, distinct from those people with jobs and upper-crust lifestyles, we must view the poor as a part of the societal structure as a whole [8]. Subsequently, meeting the needs of the poor, including basic health care needs, are essential to understanding our social responsibilities to the working poor.

Some theorists believe that most Americans will experience some level of poverty at some point in their lives [5]. Whether it is during their youth as individuals unable to provide for their families, or as elderly, attempting to meet their financial obligations while collecting social security, the impact that this revelation has on the society as a whole should be noted. Recognizing the role that health care and health care expenses have on perceptions of poverty is an important consideration. Contrary to popular belief, poverty impacts families who are working, mothers attempting to provide for their children, and a large population of those seeking work who cannot find it. The belief that poverty only impacts single mothers of young children who hope to continue in the system is a concept challenged by theorists like Rank, and should be assessed when determining the populations being served by reform efforts in health care.

\section{Health care and the elderly}

Another central consideration when evaluating the nature of health care in this country and the expenditures related to the process of care is the obligation we have, whether political or ethical, for the care of the nation's elderly. The American population is growing older every day, and this "graying" of the American population will have an impact on how health care resources are allocated, how health professionals address both short and long-term care scenarios and how the workforce in the health care sector will meet the needs of a growing geriatric population. Research indicates that between 2005 to 2030, "it is estimated that the number of adults aged 65 and older will almost double from $37,000,000$ to over 70,000,000, increasing from 12 percent of the population of the United States to almost 20 percent of the population" [9]. This shift in the demographic composition of the country will have a broad range of impacts, including a sharp rise in the number of individuals who disabled. "Between 2000 and 2040 the number of older adults who are disabled will more than double, increasing from an estimated 10,000,000 to an estimated 21,000,000" [8].
The Eldercare Workforce Alliance maintains that there is a need to address the health care needs of adults in this country who are underinsured or uninsured because of the changing demographic composition of the nation and the rise in the population over the age of 85 [10]. The population over the age of 85 in this country is the fastest growing demographic group, while also the largest segment of the population requiring direct and skilled nursing care [10]. "Inadequate training in geriatrics, chronic care management, and longterm care leads to misdiagnoses, medication errors, and poor care coordination-resulting in substandard care and higher costs" [10].

Genaro Armas, in his article "People 65-plus Increase by 300\%", provided some documentation regarding the increasing elderly population in this country and the possible impacts in terms of provisions in healthcare and the costs involved. Armas stated that the number of people over the age of 65 years throughout the world will increase to some 420 million, a figure that has tripled over the past 50 years. The US Census Bureau also supports this figure by demonstrating that this has occurred in the United States.

Armas argued, though, that the quality of life and the views of the elderly vary significantly by culture, and different cultures place different values on their elderly. As individuals age, their activities inherently slow down. This creates a division between the speed of youth and the view that age results in a slowing of senses, capabilities, and responses

Kathleen Berger [11], in her book The Developing Person Through the Life Span, recognized that the elderly population in the world is constantly increasing and that improvements in health and living conditions have transformed this population in recent years. Initial projections about this kind of population shift and increases in the population of people over the age of 65 have determined concerns from everything from meeting the healthcare needs of this population to the problems related the cost of care and lack of insurance. Population projections in the 1980s and early 1990s determined assessments of the viability of any proposed national health system and suggested that if seniors did not work longer, the quality of life and their economic stability would decline. These issues are just some of the many issues facing legislators considering the expenditures related to health and the ability to implement any kind of program for health care access.

Because of the requirements of this population and the sheer size of the population, the aging of the American population will inherently impact the healthcare workforce more than any other segment of the population. Because of current nursing shortages and problems in maintaining the service orientation in the clinical setting with current staffing issues and the current population of patients, the view of a growing population of individuals needing services suggests considerable problems in the years to come.

\section{The economics of insurance}

The current economic conditions in this country, including the recession and the high unemployment rate $(9.5 \%)$ may have an impact on perceptions of need regarding health care access and insurance. The current focus on new job development and reeducation of individuals who are unemployed may take steam away from efforts to apply a national health systems, but will not negate the fact that large portion of the population lacks adequate health care resources.

Employers that provide support for health insurance as a part of employment packages have experienced a shift in their contributions, 
and have passed some of this cost on to their employees. The following reflect these changes:

- The employer contribution has soared from $\$ 4,247$ in 1999 to $\$ 9,325$ in 2008 with a $119 \%$ increase.

- During the same period, employee contributions have increased from $\$ 1,543$ to $\$ 3,354$ in 2008 at $117 \%$ increase.

- Total expenses increased from $\$ 5,791$ to $\$ 12,680$ a $119 \%$ increase [12].

In order to meet the changing needs of the population, insurance companies have determined ways of moving individuals towards health insurance participation. Lee and Zapert [13] recognized that a variety of products have come out of the debate, including a plethora of high-deductible health insurance plans, which provide individuals with coverage after the payment of large deductibles. Employers struggling with the high cost of health insurance for their employees often integrate these types of plans as a means of cost savings.

For decades, many employers have used managed care plans, HMOs, PPOs and other plans that integrated restrictions on the services that an individual could select, including the providers that could be used, as a basis for creating care while also maintaining costeffectiveness. In recent years, the rising cost of healthcare has led employers to pass on the costs of healthcare to their employees [14]. The increasing use of health savings accounts (HSAs) in conjunction with high-deductible health insurance plans has been viewed as one means of creating more effective responses to health insurance needs while also lower overall costs [13].

Lee and Zapert [13] assessed the impacts of the use of highdeductible health insurance plans in conjunction with as well as separate from the use of health savings accounts (HSAs). One of the key aspects about this research was the author's attempt to determine whether individuals with high-deductible health insurance plans actually sought health care when needed, or if the presence of high deductibles was cost-prohibitive to ensuring access to healthcare. Approximately $1 / 4$ of all insured individuals in the United States are insured using high-deductible health insurance plans. This places the responsibility of paying for a minimum of the first $\$ 1000$ of care in the hands of the individuals who are insured, requiring considerable outof-pocket expenses before any real benefits can be produced from the presence of health insurance. While this may not have a major impact on individuals who have weighty health issues, those that require the immediate payment of the $\$ 1000$ and subsequent use of hundreds of thousands of dollars of insured services, the average family seeking to maintain cost savings in the presence of these plans may avoid basic services, from immunizations to pap smears and yearly physicals, as a result of the costs.

The researchers subsequently sought to determine whether individuals who are insured under these plans have the ability to meet their financial obligation regarding health care in order to obtain services after the deductible is met. Correspondingly, the researchers found that when individuals were covered for basic services, including physician's appointments, general health care, immunizations and the use of general testing services, including breast examinations and pap smears, they are more likely to have positive outcomes from treatment when it is necessary. Increasing health is a reflection of the application of wellness programming and the use of evaluative tools that can reduce the prevalence of health issues through diagnostic testing [15].
The problem of shifting the cost of healthcare to the consumers is at the center of debates over healthcare reform, the need for legislative changes, and the call for improvements in the existing system. Lee and Zapert [13] argued that the stakes are too high, the costs of health care issues in the absence of preventative care places additional burden on employers, insurers, healthcare providers and the population at large. Improving plans rather than shifting the cost towards the consumer is clearly at the heart of the modern healthcare debate.

Though the cost structure of these types of high-deductible health insurance plans provides a means of securing coverage after the deductible at a lower cost, the price of the deductible itself could result in underuse of the insurance in general. The lack of preventative care can have a negative impact on the overall cost of insurance if individuals develop long-term complications from the lack of preventative care or early care for the maintenance of specific diseases. Developing a strategy to address the issue of healthcare and provide a basic structure through which health insurance can be obtained is beneficial, but must be weighed against the issues caused by the use of high deductibles. Because quality of care is defined within the scope of preventative efforts as well as the immediacy of care, the ability of individuals to readily access care must be considered as a component of debates. The use of high-deductible insurance, while providing basic insurance, also can limit the access to care for each individual based on the lack of finances to pay for high deductibles.

The existing research suggests that the health care system in this country lacks an effective method of response to the needs of the poor, the elderly, and even the working class. In essence, the large health insurance companies and health care organizations have grown wealthy on the backs of the working class, and many still cannot afford to seek preventative care. One of the factors that is often ignored in rhetoric about health care reforms is the amount of money that could be saved simply by ensuring that pregnant mothers have adequate prenatal care, preventative services are used with regularity, and health care screening becomes a part of affordable care. States that have implemented health care programs that provide for individual coverage have demonstrated clear gains from improving access to these types of services.

\section{The Role of the State Governments}

As has been previously addressed, the expense of providing individual insurance coverage for a family can be astronomical. In fact, families that can obtain health insurance often find that the cost is prohibitive and the subsequent cost of deductibles or co-payments reduce the chances that families will access health care. The health insurance costs in the United States are often prohibitive for middle class families. Both California and Massachusetts have taken steps to address the needs of their states' uninsured or underinsured, including the large percentage of children needing medical services.

\section{State efforts}

The number of uninsured individuals in the United States has increased in the past 10 years. One reason for the dramatic increase is the determination of the cutoff point for public assistance (Medicaid), which has been frozen to keep eligible populations down. The fewer people eligible for public medical benefits (Medicaid) increase the number of people in need of health insurance. At the same time, decreases in Medicare services have been paralleled by increases in 
health insurance costs. More and more the health care dilemma cripples the struggling workers.

Adults younger than 65 who lacked private health insurance were 35 percent more likely to die between 1986 and 1995 than similar adults who did have insurance, according to a recent study released by the University of Colorado at Boulder [15].

Even when care providers are willing to consider serving populations without reimbursement, services are often never received. The problem exists because of years of abuses in the medical community. The homeless and the poor no longer view hospitals and clinics a haven for improved health. Instead, after decades battling to receive basic care, many homeless and poor refuse treatment to avoid the prejudices hospitals support. The positive gains that can be derived from preventative care models under a single-payer health care initiative would far outweigh the issues that extend from a lack of appropriate and timely care for the homeless. In this area, health care providers also benefit from the ability to address the needs of this uninsured population and provide better treatment, reducing the impacts of the "hostile" environment created by estrangement between providers and those seeking care [16].

The government also benefits from the application of a single-payer health care initiative in Massachusetts. The United States is one of the few countries in the industrialized world that does not provide health care coverage for all of its citizens. The response of governments like Massachusetts in addressing this problem indicates a progressive view of the impact of health care. Preventative care models that can be achieved through the single-payer program provides support for reductions in workplace absenteeism, increasing productivity in the private sector, and improvements in the function of government in response to the needs of the people. Though this program may challenge the government of Massachusetts in terms of the management of the program, it also promotes a progressive view of the value of the citizenry and the value of health for all people.

Weighing the positives and negatives of single-payer health care requires a microeconomic view of the issues, but it is evident that the benefits far outweigh the costs of this type of initiative. This is why considerable emphasis has been placed on this type of program through the Massachusetts legislative body, and why many democrats in Massachusetts continue to support the Mass-Care initiative.

Andreopoulos [17] maintained "It now appears doubtful that states can affect health-care reform." The health crisis is a national problem and it will need to be resolved on a national basis. To support his assertion Andreopoulos [17] noted that the state of Washington mandated universal coverage in 1993 and insurers became so angry some of them left the state [17]. The Republicans took over the State House with the goal of fixing the problem, which left 13 percent of the state's citizens without health coverage of any kind [17]. Hawaii was a pioneer with their health coverage policies in effect since 1975 but the economic downtown in the 1990 s required them to cut benefits, leaving 12 percent of the state's citizens without health insurance [17]. Oregon and Tennessee tried the same thing but had to cut the programs because the costs became greater than the revenue [17].

Nearly seven million Californians are completely uninsured, 70 percent of which have employment but do not receive healthcare benefits from their employer [18]. Most Californians fall into the category of individuals who are underinsured, people and families who have health insurance that only partially covers their health care use [18]. In 2005, approximately 2 million Americans, 3/4 of whom had some form of health insurance, declared personal bankruptcy as a result of impending medical bills and their inability to pay $[18,19]$.

Many economists in the field of healthcare have maintained that the cost of the lack of health care coverage can far outweigh the probable expenditures incurred if the State government were to pursue a mandatory health care program. Because between 15 and $27 \%$ of the uninsured individuals nationwide are children, the impact of the lack of coverage can be devastating. Many major illnesses can be attributed to the lack of proper medical care for children. Many parents attempt to meet the out of pocket expenses for things like vaccinations, general wellness visits and yearly health screenings, but these expenses can be prohibitive of the families ability to provide appropriate medical care.

Even when care providers are willing to consider serving populations without reimbursement, services are often never received. The problem exists because of years of abuses in the medical community. The homeless and the poor no longer view hospitals and clinics as havens for improved health. Instead, after decades battling to receive basic care, many homeless and poor refuse treatment to avoid the prejudices hospitals support. Health care professional, including doctors and nursing staff, are often reluctant to provide compassionate care for people demonstrating problems in paying for services.

The impetus for assessing the plight of the underinsured extended from what many perceive as the failure of reform efforts to health care in the 1990s and general disillusionment about the ability of the country to provide support for an increasing number of underinsure and uninsured [20]. Efforts by national legislators to implement a universal access program for health and mental health care has led to the general belief of the government's inability to meet the needs of millions of Americans [20]. In conjunction, the seriousness of the problem has led to regional changes, including turning to state governments to meet the needs of their constituencies.

Frist [21] maintains that the underlying reason for a governmental response to health care inequities extends from the variety of factors (race, income, regionality) that impact health care access disparities and the belief that socioeconomic conditions should not define access to health care. In an effort to define a path towards health care equity, Duncan, Quarells and Jones [22] maintain that factors impacting access should be at the center of methods for change.

The primary objective of a health care delivery system is "to enable all citizens to access health care services that are cost-effective and that meet certain pre-established standards of quality" [23]. However, this is hardly the case in California where health insurance benefits the rich while leaving the poor to fend for themselves. Employee benefits play a significant role in the extent to which lower class individuals are able to obtain adequate medical care. The primary reason for employers to purchase insurance plans is to provide their workers with the opportunity to afford insurance that would otherwise be far too expensive if purchased as an individual policy. Correspondingly, the reason why many Californians have little or no coverage in spite of the existence of public and private health insurance programs is because it is far too expensive if an employer is not subsidizing the individual. Indeed, the United States health care market is referred to as "imperfect" because it does not allow for all people to take advantage of medical services- only those who are either covered through employers or can afford their own private policies.

The major players in the United States health services system include physicians, health service institution administrators, insurance companies, large employers and the government [23]. The negative 
effects of the often-conflicting self-interests of these players are extreme difficulty keeping tabs on myriad health plans; significant need for numerous claims processors; detail-oriented payment requirements that often result in denied claims, which in turn require more processing; issues with partial payment; lengthy collection efforts; and complex government programs. The positives are few and far between in a system that costs itself untold numbers of unnecessary expenses in exchange for comprehensive coverage for all [23].

Understanding the gross inadequacy of California's health insurance programs requires one to also understand the nature of medicine and the history that has brought the industry where it is today. Professionalization of medicine started later in the United States than in some Western European nations because the United States did not address necessary issues that required attention prior to its medical system adopting a professional stance. Medicine had a domestic rather than a professional character in the preindustrial era because there were so many issues surrounding the industry's professional character. Urbanization changed that by bringing to light the need for technological advancement, as well as creating "increased alliance on the specialized skills of paid professionals" [23].

Professional physician services were inadequate in the preindustrial era due to disarray of medical practice; primitive procedures; missing institutional core; unstable demand; and disorganization of medical education [23]. Scientific medicine and technology changed that by improving technique, education and equipment. The emergence of general hospitals strengthened the professional sovereignty of physicians by encouraging a common interest among physicians, as well as affording them a "well-organized medical profession" [23]. Seven primary elements that helped move this along included: urbanization; science and technology; institutionalization; dependency; cohesiveness and organization; licensing; and educational reform [23]. Contract practice and prepaid group practice were the prototypes of today's managed care plans because with contract practice, the control of excessive utilization and traditional fee-forservice formats were highly preferred, while with prepaid group practice provided consumers with comprehensive coverage for one fee.

\section{Mandates}

States like Massachusetts have already implemented mandatory insurance programs designed to require insurance coverage for all citizens of Massachusetts and support the introduction of new insurance for the uninsured and underinsured. The problem has been posed for states like Massachusetts and California because of the costs, both actual and hidden, to modern society that result from a lack of health insurance and healthcare access.

Researchers maintain the lack of health insurance have hidden societal costs, which must be considered when calling for the creation of a national or regional health care program [24]. Individuals without health insurance coverage tend to have poorer health and live shorter lives than those with insurance [24]. Heavy reliance on Medicare and disability payments as a result of poorer health show consistent costs of lack of insurance or underinsurance in this country, to the tune of $\$ 65$ $\$ 130$ billion each year [24]. In conjunction with this, some of these costs are expended by the states in which the underinsured or uninsured live, suggesting that if a national program is not adopted, states like California can't afford not to implement changes [24].

A proposal for single-payer health care, outlined by Mass-Care supporters and state legislators like Congressman Tierney, reflects the interests of households in Massachusetts and benefits healthcare providers, non-health sector employees and the government in a number of specific ways. Though opposed by health insurance companies, the proposal reflects the best interest for the largest number of people.

Any theoretical analysis of the proposed single-payer health care initiative requires an understanding of constrained optimization. In essence, the benefits of this type of program have to be weighed against the specific constraints, including the cost and management of the single-payer health care system. At the same time, it must also be recognized that the issue of uninsured and underinsured individuals in the state, and the household expenditures for private-pay insurance are elements that can be weighed against the costs of the single-payer health care initiative.

\section{State success or failure}

Reform efforts to bring in state-run health insurance have been unsuccessful in California due in combination to the roles of medicine, the middle class and American beliefs/values those with money have typically controlled whether or not the health care system is modified. The factors that ultimately led to the passage of Medicare and Medicaid included cross-subsidization and the protection of the elderly and poor; however, they have failed in preventing such occurrences of treatment denial based upon financial considerations. "Medicaid and Medicare are prime representations of the public sector in the amalgam of private and public approaches for providing access to health care in the United States" [23].

Indeed, health care reform has been a thorn in the nation's side ever since the development of private insurance and employer-supplied coverage after World War II. This union-supported venture did not sit well with subsequent presidents, such as Truman, who tried hard to reform health care so as to reflect a more comprehensive and viable commodity for all Americans. Clinton even took a shot at it, however, one might readily argue that his was the most catastrophic failure of all attempts made in past decades, with then President Johnson's passing of Medicare and Medicaid proving to be the only successful endeavor [25]. "The campaign for some form of universal government-funded health care has stretched for nearly a century in the U.S. On several occasions, advocates believed they were on the verge of success; yet each time they faced defeat. The evolution of these efforts and the reasons for their failure make for an intriguing lesson in American history, ideology, and character" [26]. Leaving the entire burden upon employers as a means by which to subsidize a failing health care system creates an even greater impact upon the extent to which California's lower class individuals are able to obtain any sort of adequate insurance coverage.

The fact is that 19 governors have tried to pass some form of universal health care in their states with more than 10,000 separate bills related to health care coverage underscores how widespread the problem is. Massachusetts' universal health care plan is an example of one such plan that has worked relatively well, but as analysts have pointed out, this is a wealthier state with the fewest citizens without insurance [17]. The 2009 state budget allocates $\$ 13,540.554$ for health and human services [27]. Compare this to $\$ 6,250,031$ budgeted for education and $\$ 1,142,5614$ budgeted for public safety [27]. The budget for health and human services is the largest expenditure in the 2009 budget. 
Massachusetts' success or failure cannot really be translated to other states. Wisconsin adopted such a policy in 2007 to the consternation of political analysts. Every person under the age of 65 is covered by a single-payer universal policy at a cost of approximately $\$ 15.2$ billion [28]. That's more than $\$ 3$ billion than the state's revenues, which would translate to an additional $\$ 510$ per month for every person who works [28].

Companies would be paying an aggregate of 29.8 percent in federal and state payroll taxes [28]. Besides these higher payroll taxes, the Wisconsin Senate also passed a $\$ 1.25$ per pack of cigarettes, a 10 percent increase in corporate tax, and they adopted new fees for cars, hospitals, real estate transactions and trucks [28]. Overall, the average taxpayer would see their own taxes increase to 20 percent of their income. This plan resulted in such concern over the economics that the Wisconsin House did not approve the plan.

The State of Massachusetts' revenue comes from a long list of sources and a range of funding mechanisms, some of which include: taxes on alcoholic beverages, cigarettes, corporations, deeds, estate inheritance, financial institutions, income, insurance, motor fuels, public utilities, room occupancy, sales - regular, sales-meals, salesmotor vehicles, miscellaneous, and unemployment insurance surcharges [27]. These are under the category of "Consensus Tax Revenue" [27].

The funds for the Commonwealth of Massachusetts are divided into three major categories: Governmental Funds, Proprietary Funds and Fiduciary Funds. Governmental funds are those used to operate the government and provide state-paid for services [29]. Health care is one of those expenditures as is school construction and roads. The amount of taxes and other fees collected by the state will increase or decrease the amount needed for governmental funds. The 2006 financial report reported proprietary assets of $\$ 1,291,745,000$ [29]. The state also had long-term assets and investments and liabilities against that with a total of $\$ 3,648,410,000$ in net assets [29]. An overall deficit of $\$ 753,082,000$ was realized in 2006 [29]. Things that impact the amount in these funds would include federal funding for certain things, like school programs and Medicaid.

Fiduciary funds include items like pension trust funds, external investment trust funds, private purpose funds and agency funds [27]. The total identified on the 2006 financial report was $\$ 47,538,097,000$, liabilities against these funds total $\$ 3,415,020,000$ and net assets total $\$ 44,123,077,000$. The amount collected from payrolls for social security would affect the amount of money the state had for these expenditures.

Revenue projections are made based on the information that is known at that time. Beacon Hill Institute at Suffolk University in Boston, forecasts revenue for the state each year. In January 2007 it offered revenue forecasts for both 2007 and 2008, each with an increase. The forecast suggested the state would realize a 3.4 percent increase in 2007 and a 6.4 percent increase in 2008 [30]. This was based on a historical average increase between 1981 and 2006 and the fact that the state had never had an increase of less than 5 percent for two consecutive years [30]. The state had seen consistent revenue increases emanating from the technology and science sectors [30].

The forecasters had no way of knowing the U.S. economy would be turned on its head with soaring oil prices, which impacts all sources of power, e.g., electricity, heating oil and the numerous products that use oil as well as all the products that require fuel to transport them to stores, etc. As we also all know, there was a dramatic increase in home foreclosures due to unscrupulous persons in the financial sector. As the economy continues to tighten, more people are losing their jobs and when people who were financially stable and could afford the house and other things they bought are suddenly unemployed, more defaults occur. Any ripple in the economy has a direct impact on any budget, from an individual through the federal government. As for Massachusetts, higher unemployment means less income tax and less sales tax. Mortgage foreclosures mean a temporary reduction in the amount of property taxes they collect and decreases in state sales taxes resulting from declining individual purchasing. Unfortunately, these factors may have a lasting impact on the ability of the state to demonstrate fiscal health and in relating directly to the continuation of the state-operated health care system.

\section{State focus on Medicare and controls}

The state of California has an extensive Medicare system that focuses on a variety of programs for adults and children based on income. Medicare Advantage or Part C Medicare programs are constructed in a number of ways to provide funding for private insurance companies to provide health services to beneficiaries [31]. Medicare Advantage programs are created to work in concert with Medicare Part A and Medicare Part B programs, requiring enrollment and continued payment of Medicare Part B premiums as a component of participation. These programs are created in contrast to the fee-forservice Medicare option [31]. Individuals can select their Medicare Advantage Plan option based on the types of services that are desirable and the costs associated with these plans.

The most commonly used Medicare Advantage plans offered in California include: 1. Health maintenance organizations (HMOs); 2. Preferred provider organizations (PPOs); 3. Private fee-for-service (PFFS) Plans; 4. Special needs plans (SNPs); and 5. Medical savings accounts (MSAs) [31]. In addition to these plans, there are some other employee-sponsored plans, often created to provide services for an employer's retirees, which are also considered under the scope of Medicaid Advantage plan options [31].

Health maintenance organizations (HMOs) under Medicaid focus on the use of doctors and facilities that are within a network in order to provide benefits. If individuals decide to go to service providers outside of the HMO network, these services are not reimbursed unless they are used in conjunction with an urgent care scenario [31]. HMOs are the most frequently selected Medicaid Advantage Plans utilized in California and each HMO program has a distinct set of program requirements, identified within the program specifications.

Preferred provider organizations (PPOs) are the second most commonly used form of Medicare Advantage program in the state and it is organized around a network of listed providers. When individuals seek treatment from providers within the PPO, the co-payment is lower than that paid to providers outside the PPO. In addition, though, California has also linked Medicare prescription drug coverage to the single PPO available in the state, and this PPO has a required deductible that has to be met before benefits are paid out under the program, with exceptions being given for regular doctor visits and preventative services [31].

Private fee-for-services (PFFS) plans are also offered in California, and these are plans that allow individuals to use any physicians that are approved by Medicare, as long as the terms of the program are met and the health care providers agree to meet the requirements of the plan. This type of plan allows private insurance companies to determine how much will be reimbursed for the use of specific physicians and 
subsequently determine how much will be paid for the services that a patient receives from a provider [31]. Depending on the plan carrier and the nature of the plan itself, drug coverage may be an option.

California also allows for the integration of Medicare special needs plans (SNPs), which are created to meet the needs of specific populations. In California, this may include people who are enrolled and participating in long-term care facilities; people who are eligible for more than one other program, and people who have disabilities or chronic conditions that impact program requirements or participation [31]. These SNPs are not available in all areas of California, and were created to develop a kind of focused care approach for people with distinct needs [31].

Medical Savings Accounts (MSAs) are also available in California, but have only been available since 2007 . These MSAs were created to provide coverage, while also creating a different approach to the funding mechanism. California approved MSAs have two components: a high-deductible health plan, that covers Medicare Part A and B services out of the deductible; and a medical savings account, which is used to bank Medicare deposits that can be used to offset health care services and the high deductible payments that correspond with the first segment of the plan [31]. These plans do not provide for prescription drug coverage and are currently available throughout California, except for the following six counties: Glenn, Inyo, Lassen, Los Angeles, Marin and Orange [31].

In addition, California Healthy Families program is an extension of the national CHIP [32], which provides support for children who do not qualify for the state's Medi-Cal free insurance program [33]. In 2009 , the programs premium increased to from $\$ 13-48$ for Category B participants and from $\$ 21-72$ for Category C participants. Categories are income-based, with the primary goal of meeting the insurance needs to ensure that children are able to seek out medical treatment on a regular basis $[34,35]$.

The programs developed were designed to address California's need for affordable health care and the problem of affordability for low to moderate-income families. While the States' Medicaid program adequately meets the healthcare needs of the welfare and low-income families, the issue of affordability gets more complicated for families with regular incomes above the poverty level.

In the State of California, the segment of the population age 18 and under is $27 \%$ of the population, which is approximately $9,966,800$ people [34]. Of that number, a full $1 / 4$ of the state's children are currently living in poverty. Of this group, a large population is comprised of ethnic minorities, with $56.4 \%$ of the people living in poverty in the state of either Black or Hispanic decent [34]. One of the major shortfalls of the state's programs is that there is the problem of meeting the needs of the state's undocumented children, children of undocumented immigrants who require health services and cannot obtain health services within the existing system. As the current system becomes more complicated, a growing number of hospitals are going to begin rejecting individuals who cannot show an ability to pay for services and cannot be processed as a part of the Medicare system. This underscores the need for some methods to providing care that address the issue of resources, especially for children.

Like Massachusetts, California has recognized the inequities that exist in access to healthcare and the impacts and have proposed methods to address health care in response to this issue. In addition, researchers maintain that the lack of access to healthcare and the lack of insurance have a kind of snowball effect on regional costs, because those without effective care have poorer health and are more dependent on disability than those who can continue working. Poor medical outcomes are often linked to lack of access to medical care for preventable or treatable conditions [18].

\section{Previous National Proposals}

The concept of a national health or single-payer health program for the United States is not a new concept, and organizations have offered up distinct proposals since the 1940s. "Starting with Harry Truman in the 1940s, Richard Nixon in the 1970s, and Bill Clinton in the 1990s, all of them attempted change in the health care system and enacted some kind of national health insurance" [12]. Most proposals are based on two specific imperatives: the fact that the United States spends the most on health care of any of the developed nations of the world and yet ranks as low as $37^{\text {th }}$ in terms of the quality of health care. While we spend the most money, many of our citizens go without services and preventative care is a relative pipedream for many Americans.

In order to create a political impetus for change, most proposals begin with an explanation of how the United States underserves its population in relation to health care, and health care conglomerates and insurance companies have driven free-market prices through the roof. Davis et al. [36] argued that despite massive expenditures and exorbitant per capita health care costs, United States health care organizations continue to underperform when compared to national health programs in other countries. The United States system is more costly and less effective than the systems in Australia, Canada, Germany, New Zealand and the United Kingdom in relation to most of the following dimensions of performance: quality, access to care, efficiency, equity and healthy living (Table 1) [36]. In fact, the United States is the only country of those mentioned that does not have universal health insurance coverage, and Davis et al. [36], maintained that this was the result of political economics, rather than a truthful assessment of the poor performance and problematic conditions effective American health.

For decades, political economists have maintained that some aspects of the health care system in this country will improve after time following the adoption of information technologies and standardized methods of providing care. In truth, though, these measures have become an excuse for increasing costs in health care, based on the argument that the health care organizations cannot absorb the costs of high technology and still meet their shareholder obligation. Surveys of both physicians and patients have resulted in a reflection on experiences in health care in this country that is troubling.

Davis et al. [36] maintained that the lack of universal health care coverage is the most notable difference when comparing the countries mentioned, and this standard of coverage is the best method for determining accessibility of care. This country has also fallen behind others in the implementation of technologies and medical advancements, including improvements in standards and quality of care and this is a direct result of the lack of government involvement in the free-market system. Simply put, the laws of supply and demand allow America's hospitals to provide inadequate care while charging the highest prices because they can.

Out of all the areas assessed as a component of health care service planning in the comparison of the countries identified, the U.S. did best in terms of preventative are strategies, though this is a modest gain [36]. Even so, the U.S. has not made strides in helping individuals' lead healthier lifestyles, an element that not only corresponds with 
preventative care, but also with regular family medicine services provided outside of the emergency room setting.

\begin{tabular}{|c|c|c|c|c|c|c|}
\hline $\begin{array}{lr}\text { Six } & \text { Nation } \\
\text { Summary } & \text { Scores } \\
\text { on Health } & \text { System } \\
\text { Performance }\end{array}$ & $\begin{array}{l}\text { Australi } \\
\text { a }\end{array}$ & $\begin{array}{l}\text { Canad } \\
\text { a }\end{array}$ & $\begin{array}{l}\text { German } \\
y\end{array}$ & $\begin{array}{l}\text { New } \\
\text { Zealan } \\
\text { d }\end{array}$ & UK & USA \\
\hline Overall Ranking & 3.5 & 5 & 2 & 3.5 & 1 & 6 \\
\hline Quality Care & 4 & 6 & 2.5 & 2.5 & 1 & 5 \\
\hline Right Care & 5 & 6 & 3 & 4 & 2 & 1 \\
\hline Safe Care & 4 & 5 & 1 & 3 & 2 & 6 \\
\hline Coordinated Care & 3 & 6 & 4 & 2 & 1 & 5 \\
\hline $\begin{array}{l}\text { Patient-Centered } \\
\text { Care }\end{array}$ & 3 & 6 & 2 & 1 & 4 & 5 \\
\hline Access & 3 & 5 & 1 & 2 & 4 & 6 \\
\hline Efficiency & 4 & 5 & 3 & 2 & 1 & 6 \\
\hline Equity & 2 & 5 & 4 & 3 & 1 & 6 \\
\hline Healthy Lives & 1 & 3 & 2 & 4.5 & 4.5 & 6 \\
\hline $\begin{array}{l}\text { Health Expenditures } \\
\text { per Capita* }\end{array}$ & $\$ 2,876$ & $\$ 3,165$ & $\$ 3,005$ & $\$ 2,083$ & $\begin{array}{l}\$ 2,54 \\
6\end{array}$ & $\begin{array}{l}\$ 6,10 \\
2\end{array}$ \\
\hline
\end{tabular}

Table 1: Six nation summary of health system peformance.

The following are the major findings of a comparative study of the United States and other developed nations:

- Quality: The indicators of quality were grouped into four categories: right (or effective) care, safe care, coordinated care, and patient-centered care. Compared with the other five countries, the US fares best on provision and receipt of preventive care, a dimension of "right care". However, its low scores on chronic care management and safe, coordinated, and patient-centered care pull its overall quality score down. Other countries are further along than the U.S. in using information technology and a team approach to manage chronic conditions and coordinate care. Information systems in countries like Germany, New Zealand, and the U.K. enhance the ability of physicians to identify and monitor patients with chronic conditions. Such systems also make it easy for physicians to print out medication lists, including those prescribed by other physicians. Nurses' help patients manage their chronic diseases, with those services financed by governmental programs.

- Access: Not surprising-given the absence of universal coveragepeople in the U.S. go without needed health care because of cost more often than people do in the other countries. Americans were the most likely to say they had access problems related to cost, but if insured, patients in the U.S. have rapid access to specialized health care services. In other countries, like the U.K and Canada, patients have little to no financial burden, but experience long wait times for such specialized services. The U.S. and Canada rank lowest on the prompt accessibility of appointments with physicians, with patients more likely to report waiting six or more days for an appointment when needing care. Germany scores well on patients' perceptions of access to care on nights and weekends and on the ability of primary care practices to make arrangements for patients to receive care when the office is closed. Overall, Germany ranks first on access.
- Efficiency: On indicators of efficiency, the U.S. ranks last among the six countries, with the U.K. and New Zealand ranking first and second, respectively. The U.S. has poor performance on measures of national health expenditures and administrative costs as well as on measures of the use of information technology and multidisciplinary teams. Also, of sicker respondents who visited the emergency room, those in Germany and New Zealand are less likely to have done so for a condition that could have been treated by a regular doctor, had one been available.

- Equity: The U.S. ranks a clear last on all measures of equity. Americans with below-average incomes were much more likely than their counterparts in other countries to report not visiting a physician when sick, not getting a recommended test, treatment or follow-up care, not filling a prescription, or not seeing a dentist when needed because of costs. On each of these indicators, more than two-fifths of lower-income adults in the U.S. said they went without needed care because of costs in the past year.

- Healthy lives: The U.S. ranks last overall with poor scores on all three indicators of healthy lives. The U.S. and U.K. had much higher death rates in 1998 from conditions amenable to medical care-with rates 25 to 50 percent higher than Canada and Australia. Overall, Australia ranks highest on healthy lives, scoring first or second on all of the indicators [36].

The findings underscore the need to address some of the essential problems in this country related to providing health care in a manner that allows for equity in access and improves outcomes.

\section{Physician's plans}

In 1989, a group of American Medical Association physicians created a plan to address what they perceived as a growing health care dilemma in this country and the potential for a health care crisis over the next two decades. These physicians proposed a single-payer national health program which would address some of the central inequities in access to care and availability of health care resources. Published in the New England Journal of Medicine, this proposal was a comprehensive plan that addressed many of the issues currently facing our country and our politicians.

Specifically, these physicians noted more than two decades ago that the health care system in this country was failing and at that time, tens of millions of people were without health insurance and the costs involved were spiraling out of control. At the same time, the physicians also noted that federal bureaucracy was making aspects of their job unmanageable and resources were not being allocated with equity [37]. The proposal introduced in 1989 was supposed to address the following six point's seen as absent from the current health care paradigms. It would

- fully cover everyone under a single, comprehensive public insurance program;

- pay hospitals and nursing homes a total (global) annual amount to cover all operating expenses;

\section{- fund capital costs through separate appropriations;}

- pay for physicians' services and ambulatory services in any of three ways: through fee-for-service payments with a simplified fee schedule and mandatory acceptance of the national health program payment as the total payment for a service or procedure (assignment), 
through global budgets for hospitals and clinics employing salaried physicians, or on a per capital basis (capitation);

- be funded, at least initially, from the same sources as at present, but with payments disbursed from a single pool; and

- contain costs through savings on billing and bureaucracy, improved health planning, and the ability of the national health program, as the single payer for services to establish overall spending limits [37].

It was not the expectation of these physicians that this plan would not be universally accepted, or that it would be immediately adopted. Instead, the physicians offered the plan as a method of creating dialogue into ways that could be developed to control costs, reduce competition, and address the profits derived at the expense of the nation's health. One of the more important aspects of the plan that has been addressed in subsequent plans is the administration of services; it was the expectation of the physicians proposing these changes that the program be federally mandated and funded, but state and locally administered [37]. This plan introduced some intriguing elements into the debate about the role of government in ensuring access to health care for all. The physicians maintained a positive view of Canada's health care plan, which conveys considerable administrative responsibilities to Canada's proveniences much in the same way that the U.S. system would rely on the work at state and local levels.

This 1989 plan addressed major elements of a national health or single-payer program, including who and what is covered, how payment for hospital and physician services are determined, what factors determine payment methods for ambulatory care and longterm care procedures, and how funding mechanisms are developed and funding sources maintained [37]. Though this plan integrated a comprehensive approach for defining the role of government and shaping the activities of providing health care, it did not delve deeply enough into the economic factors that would drive a country in the opposite direction for more than two decades.

In relation to coverage, this physician created plan was a singlepayer public plan that would cover everyone in the country for medically necessary services, "including acute, rehabilitative, longterm, and home care; mental health services; dental services; occupational health care; prescription drugs and medical supplies; and preventive and public health measures" [37]. In order to effectively address potential abuses of the system, a board of medical experts on the state level, along with community representatives, will determine at the state level what services will be deemed necessary and which services (e.g. plastic surgery, elective surgery) will be determined unnecessary and excluded from coverage under the plan. No one under the plan would need alternative insurance coverage, though private insurers could develop auxiliary plans for uncovered surgeries. Under the national health plan, patient co-payments and deductibles would no longer be needed, and universal coverage would all but eliminate the burden on local communities, state and federal programs designed to provide care for those unable to pay.

Some of the cost savings under this plan would be derived from the lack of a free-market approach, which has resulted in the skyrocketing health care costs under the current system. When it was proposed, the physicians related the need to prohibit the use of operating funds for capital purchases and the use of profits as a main incentive for the level of care provided [37]. When individuals have the capacity for private pay for services, physicians and hospitals may be encouraged, even supported, in the widespread over use of interventions, especially when incentive fees are paid for the use of technologies, prescription medications or surgical procedures. In comparison, health maintenance organizations that maintain low cost payment systems through a process of skimping on care would also be taken out of the loop. Taking away a bottom-line approach to health care inherently improves the quality of care and reflects the importance of methods that address many of the other failures of the health care system.

In order to make the transition to a single-payer or national health program, the physicians in 1989 argued the need for a multitier approach to health care that allows some physicians to be paid in alignment with their services (based on necessary service designations by a panel). In addition, some physicians would be paid as national employees, who would receive salaries for their work in publicly funded hospitals and institutions [37].

Under the 1989 plan, a state medical society will provide a representative to work with the state national health program to create a fee-for-service binding fee schedule, and physicians will submit their billing to the national health program for reimbursement [37]. One of the key aspects of this plan has to do with the expediency of administrative processes, with a penalty paid to physicians for any bills not paid within 30 days. While this should create a motivation for administrative conciseness, it also could be a costly aspect of the plan if administrative process is not streamlined. Even in 1989, the physicians involved in the proposal recognized that computer technology could advance this area of administrative process and cut costs by creating an expedient method for bill submissions.

In order to support local administrative process, institutions, including hospitals, health centers, and nursing care facilities can ask to receive a global budget that they would administer for the participation in a delivery of care process, including providing outpatient, home care, and physician services, as well as preventative care and educational programs [37].

Because of the existing infrastructure in place and the presence of HMOs and other health care organizational structures, the plan offered by physicians in 1989 reflected the belief that these organizations can opt to be paid fees based on per capita use for outpatient and physician services, and regulations would be implemented to address capital expenditures and profits of these facilities. "Selective enrollment policies would be prohibited, and patients would be permitted to leave an HMO or other health plan with appropriate notice. Physicians working in HMOs would be salaried, and financial incentives to physicians based on the HMO's financial performance would be prohibited" [37]. This kind of pluralistic approach is necessary because of the existing operational systems, the expansive role of health maintenance organizations and the need to address methods of supporting operating costs for facilities already meeting the needs of many citizens.

One of the key benefits of this kind of program is that it will put an end to disruptions in patient care that relate to the maintaining or loss of health insurance coverage. It is not uncommon, for example, for a person to be seeing one family practitioner and then find they must change to another if their insurance changes under workplace plans. Frequently, the changes resulted in a long-standing family practitioner becoming an "out of plan" provider, which would cost the patient out of pocket funds if they chose to continue with their primary care physician. The benefits of this plan include minimization of disruptions, improvements in methods of payment, and reductions in 
activities that occur as a result of motivations and paid incentives for specific physician or practitioner decisions [37].

The funding mechanism of the 1989 proposal relates the need for federal and state funding mechanisms and the unification of Medicare and Medicaid as a part of the larger national health program. The plan proposes to set the total expenditure for the national health care plan at the proportion of the GNP for the year preceding the implementation of the plan. For example, if the plan was implemented in 2012 and the level of spending was 22 percent of the GDP for 2011, the plan's spending limit would be based on that 22 percent. Funding, then, would be capped at the percentage identified, and state and federal funds would be channeled through the program. Specifically, all funds allocated for Medicare and Medicaid would go into the national health program coffers. Correspondingly, all current state and local funds for health care will be allocated to the program, adjusted for inflation each year [37].

Taxation would also be a part of this plan, with a tax rate set and tax collections levied on all employers. Many large employers who already have existing health benefit programs for their employees will be able to credit the cost of those programs to their national health program tax liability. The taxation rate will be based on the employers' expenditures for health benefits from the previous year, adjusted for inflation [37]. Contrary to opponents of national health programming, this measure will not significantly penalize small employers who do not currently have health benefits programs, and will not unduly impact employers, because it proposed to hold total costs of taxation to the expenditures of the year prior to plan implementation [37].

General tax revenues will be handled in much the same way as the Canadian plan under this proposal [37]. Taxes could be levied in a manner that corresponds with the cost of out-of-pocket health expenses. Though Canada's plan has resulted in an increased need for funding through taxation, the use of the single-source payment construct allows for a higher degree of cost containment that can result in considerable savings and reducing inequities in the distribution of health care services. At the same time, tax reductions as a result of itemizing for medical care expenses would no longer exist, creating both a reduction in the expenditures for health care and an increased taxes collected from those who no longer pay for out-of-pocket care.

The benefits of this program include the following:

- Establishes the right to comprehensive care;

- Allows for necessary care without co-payments or deductibles;

- Allows patients to select their practitioners;

- Reduces the financial threat of illness;

- Promotes preventative care;

- Allows physicians free choice of their practice settings;

- Treatment options are not constrained by insurance limitations;

- Treatment decisions are not cost-driven;

Simplification in billing would result in cost savings;

Creates a more humane and efficient clinical setting [37].

Physicians also offered a similar plan in 2003, with a focus on the single-payer national health insurance system that would be based on the following four principles:
- Access to comprehensive health care is a human right. Coverage should not be tied to employment. Private insurance firms' past record disqualifies them from a central role in managing health care.

- The right to choose and change one's physician is fundamental to patient autonomy. Patients should be free to seek care from any licensed health care professional.

- Pursuits of corporate profit and personal fortune have no place in care giving and they create enormous waste.

- In a democracy, the public should set overall health policies. Personal medical decisions must be made by patients with their caregivers, not by corporate or government bureaucrats [38].

Again, the proposal to develop a national health insurance program like those used in most other developed nations is linked to a transition away from the current Medicare and Medicaid systems and towards coverage that is extended to all age groups [38].

One of the key aspects of this 2003 program is that it reflects the inefficiencies that have resulted in expensive privatized health insurance and incredible administrative costs involved in the competitive insurance industry. "Our multiplicity of insurers forces U.S. hospitals to spend more than twice as much as Canadian hospitals on billing and administration, and U.S. physicians to spend about 10 percent of their gross incomes on excess billing costs" [38]. Subsequently, the proposal maintains that private health insurances and HMOs consumed more than 13.6 percent of their income each year for their overhead, while both the Medicare and Canadian National Health Insurance programs have administrative costs of below 3 percent [38].

The proposal also reflects the extensive costs involved in providing emergent care services for the poor and uninsured, which often seek care after lengthy illnesses, but are unable to pay. Systems that require co-payments and deductibles actually endanger the health of those they are supposed to protect, because the sick poor do not participate in vital inpatient medical services until their illness is advanced [38]. This type of system also discourages preventative care and encourages individuals to allow health concerns to become major health problems. If treated early, many major illness, from cancer to heart disease, can be addressed at a much less costly level than if interventions occur before the illnesses become pervasive or spread [38].

Alternatives to a National Health Insurance plan have been introduced, including health reforms, improvements to Medicare, expanded coverage for Medicare and Medicaid programs, and improved efficiency [38]. Unfortunately, these alternatives, including those under President Bush in the early 2000s, did not inherently lead to improvements for at-risk or vulnerable populations.

Some of these alternatives included the following:

- "Defined contribution schemes" and other mechanisms to increase patients' price sensitivity;

- Tax subsidies and vouchers for coverage for the uninsured;

- Expansion of Medicaid, CHIP and other public programs;

- The Medicare HMO program and Medicare voucher schemes [38].

Health care reform, though, is not simply a shifting of existing methods of care or advancement of programs that have not adequately addressed the needs of the population as a whole. The National Health Insurance Program proposed by the Physicians' working group in 1989 
and again in 2003 addresses some of the ill-conceived reform schemes that have not worked and reduces reliance on the market-based strategies that do not provide a basis for improvements or increased access for the nation's poor.

\section{Legislation}

H.R. 3962, the Affordable Health Care for America Act, and H.R. 3590 [39], the Patient Protection and Affordable Care Act, were two segments of the process of creating the final revised Health Care and Education Affordability Act of 2010. H.R. 3962 was debated in the House of Representatives beginning in October of 2009 and the Senate debated H.R. 3590 [39]. In the end, the House decided to focus on a revised version of the Senate bill, giving up on H.R. 3962 in favor of a changed version of H.R. 3590 [39]. These two pieces of legislation were created to address the issue of health care reform and the need for manageable methods for ensuring health insurance coverage for large segments of the adult population currently uninsured or underinsured. The progression of the legislative process and the addition of education funding stipulations in the final legislation show how complex the process is of getting legislation passed.

Michigan Democrat John Dingell introduced H.R. 3962 as a means of adopting changes to the current health insurance and health care payment systems to increase accesses to underserved populations and improve access to care. The bill was initially introduced in the House of Representatives in October of 2009, and then sent to a variety of committees for assessment. Between October 29, 2009 and November 7,2009 , the bill was reviewed, amended, and reevaluated, including the addition of the Stupak-Pitts Amendment, which prohibited the use of abortion services for individuals receiving health insurance through public subsidies. This amendment led to controversies both in the signing of the initial House bill and later in the decisions made surrounding the passage of the amended Senate bill. In a close House vote, the amended H.R. 3962, which included the Stupak-Pitts Amendment, was passed by the House.

There were five basic aspects of H.R. 3962, which included health insurance market reforms, the creation of a Health Insurance Exchange, the introduction of a new public health insurance option overseen by the Secretary of the Department of Health and Human Services, introducing an individual mandate, outlining specific employer benefits, defining methods for subsidizing premiums, the expansion of long-term insurance planning, prevention and wellness options, and the creation of a directive for advanced care planning. The bill also focused on methods for overseeing the application of the law and for improving methods for advancing individual care, including quality improvement initiatives, physician quality reporting, and fraud services.

One of the major provisions of H.R. 3962 was the create of new standards in federal health insurance in relation to both individual and small group markets, including banning efforts by insurance companies to prevent coverage for pre-existing conditions or for rating or restricting the level of insurance that could be issued or the renewability of insurance policies based on health conditions [40]. The bill did allow for variations in premiums to be made based on some federal standards related to geographic location, age and the size of the insured's family. One of the more significant measures was to prohibit insurance companies from creating annual or lifetime limits that would prevent coverage for specific health conditions, including those that required long-term and end-of-life care [40]. Other important measures in relation to the health insurance market included allowing students to stay on their parents' insurance policies longer and to create uniform measures that allowed for plans to be offered and sold across state lines.

The bill requires that individuals obtain health insurance and provides a range of support for this to occur. For example, subsidies are paid to employers, especially small businesses, in exchange for maintaining health insurance coverage for their employees. In addition, the bill outlines changes in Medicaid coverage to allow for low-income families to obtain insurance at an affordable or subsidized rate.

The focus on prevention and wellness services was also a valuable component of this initial bill, because it provided a means of creating incentives in small businesses to improving wellness programming in the workplace setting. In order to apply all of the segments of the bill, the bill's authors also outlined grievance procedures and methods for addressing fraud and abuse, especially in relation to enrollment, affiliations, and the intent of new standards [40].

Representative Charles Rangel of New York introduced H.R. 3590 [39] in September of 2009 to the House of Representatives, which was subsequently passed in October of 2009. Once in the Senate, though, this legislation went through a number of revisions, linked to revisions made to H.R. 3962 that ultimately led to an end to the further amending of H.R. 3962 and the subsequent revision of H.R. 3590 [39]. This revised bill was voted on in March of 2010, and signed by the President on March 23, 2010 and enacted into law as the revised Health Care and Education Affordability Act of 2010. There were some significant differences between the first version of the House bill, the corresponding measures in H.R. 3962, and the end product.

Some of the changes that were adopted include provisions for allowing insurers to increase premiums based community ratings and tobacco use, rather than pre-existing conditions. The provisions for health care coverage and the mandate for individuals was essentially the same between the two laws, though the enacted law focused on the continued use of a parent's policy for adult children up to the age of 26 [40]. Both pieces of legislation focused on methods to subsidize the insurance of small companies (those with fewer than 25 employees), though minor differences existed in relation to the gross average income of those in small companies.

Federal subsidies were similarly introduced in both acts, including a transition in the method for subsidizing Medicaid for adults, and in the approach for purchasing health insurance across state boarders. Perhaps the most controversial issue, that of the payment of abortion services, was also addressed in the amendments to the first piece of legislation and in the final; the Stupak-Pitts Amendment had to be excluded from the final draft of the bill in order to ensure passage.

The arguments against these health reform bills came from two specific groups: insurers, who feared the repercussions of extensive reform measures that required adherence to policies that could be costly; and Republican leaders, many of whom maintained that the health reform measures would be costly, would require additional taxation, and would increase the deficit. Specifically, the law required that health insurers implemented minimum standards for health insurance policies and subsequently took away any caps that had been created to reduce the payment for large-scale or long-duration treatments. Coverage caps, then, were essentially removed, requiring insurers to pay a much higher price for those who have long-term illnesses or expensive treatments. The law also focused on health insurance benefits for those with pre-existing conditions, which again 
did not allow insurers to place restrictions on those who could receive coverage. These insurers, then, had a lot to lose with the passage of this legislation, and so sought methods to deter the passage through the use of lobbying and other methods for getting their message across.

One of these methods was to focus on the costs and economics of health care reform, supporting the message that reform would be costly, would result in additional taxation, and could possibly be detrimental to many health insurance providers. Specific problems that were the focus of health insurers included the call for refraining from requiring co-payments for preventative health services and the costs involved in treating individuals with long-term care needs and preexisting conditions. Proponents of the bill maintained that cost savings could be realized on a national level, rather than additional expenditures, and that these related to everything from reduced reliance on public health insurance resources to fees provided to health insurers and a broadened Medicare tax base, all of which promoted a positive economic image of the Act.

The intention of these bills and the final act were considered positive; they linked some of the widespread issues in this country, including lost productivity, lost employment and low-income status to issues related to healthcare and wellness. The purpose was to find a happy medium between the kind of national health coverage used in most developed countries throughout the world and the use of a private health insurance scenario that would address the needs of a large population of underserved Americans. The bill demonstrated the necessity for compromise; it clearly did not meet all of the goals of the author in relation to finding the best approaches to national health improvements, but it also addressed some of the major issues facing a large segment of the adult population.

H.R. 3962, the Affordable Health Care for America Act, and H.R. 3590 [39], the Patient Protection and Affordable Care Act, led to the creation of the final and Education Affordability Act of 2010 [41]. Initially, developers sought to implement a plan that mirrored some of the sentiments regarding a national health program that had been promised under the Clinton Administration and later embraced as a part of the message during Barack Obama's campaign. While the bill did not completely accomplish the efforts at providing a broad range of health care options for all citizens, it did serve as a means of compromise, advancing efforts to increase access to both health care and preventative care services for the underinsured and underserved nationwide.

\section{ObamaCare and Opposition to National Health}

One of the more memorable statements of our current President came during his Keynote Speech at the Democratic National Convention was the idea that: "It is that fundamental belief: I am my brother's keeper. I am my sister's keeper that makes this country work" [42]. Obama maintained, and was supported on a national level, that paternalism had returned to government. It was not surprising that Obama's campaign repeatedly mentioned his desire to create a national health program or health care reform efforts.

\section{Reform}

The health care reform proposal offered by President Barack Obama in February of 2009 and integrated under what many have deemed ObamaCare covers some specific principles for changing the approach that the American government has taken towards healthcare. Though general public perception is that there is a need for reform measures and improvements to provide coverage for the millions of Americans who currently do not have healthcare coverage, the costs involved in funding this kind of program have led to a variety of different proposals and criticisms about the long-term viability of the Obama plan.

Chambers and Wedel [43] describe three essential methods for assessing public policy decisions and creating an analytical view of these policies: the analytical/descriptive approach, the value-critical framework and the value-committed framework. The first approach is based on a descriptive overview and analysis of the policy or proposed policy through an evaluation of outside perspectives. Chambers and Wedel [43] suggest a movement away from this type of approach in ensuring that public policies meet the needs of the public. These authors then offer the value critical framework, which focuses on the importance of value perspectives on the evaluation of specific policies. In other words, values are no longer considered the impetus for bias; values are used to demonstrate the importance of judgments made in regards to the policy.

The final approach outlined by the authors is the value-committed framework, which takes the value-critical framework one step further, and calls for a level of activism towards policy application based on the belief that these policies should be based on social justice. Political action in the creation of policies, then, is linked to the belief that change can only be achieved through methods that rectify social and structural issues regarding the distribution of resources [43].

Each of these analytical processes provides some insight into specific aspects of the healthcare policy proposed by the Obama administration. While the first two frameworks reflect the importance of an analytical process in the development of the policy, the third framework focuses on the philosophical view of distributive justice and the need to ensure access to healthcare for all Americans.

Chambers and Wedel [43] recognized that one of the most commonly applied frameworks for relating the central perspectives in most healthcare policies is the use of an analytical/descriptive framework. This framework is based on the existing issues that fuel policy change and the costs and benefits of this kind of approach.

The substantive issues that led to the call for healthcare reform include a growing number of Americans without healthcare coverage. Essentially, then Senator Obama, in his 2008 campaign speeches, argued the necessity for political action to reduce the level of economic hardship caused by the lack of coverage for health insurance. In addition, Obama called for what many have described as a national health program. Recognizing that this country is the only country in the developed world that doesn't have a government-initiated national health program has led to the call for change.

In the planning and progression of healthcare debates over recent years, President Obama has taken some substantial acts to support the development of national health care programming. President Obama earmarked $\$ 630$ billion over a ten-year period to support reform efforts, in the form of the Health Reform Reserve Fund [44]. This funding was set aside to partially offset the cost of healthcare reform, but estimates suggest that this amount is just a drop in the bucket over that same period in terms of the overall costs of reform efforts.

When Obama's first plan came into view, it would have cost upwards of 1.6 trillion over the ten-year period, a figure that would just not pass the House and Senate scrutiny. As a result, the House cut the bill to reduce costs to less than $\$ 900$ billion, in an effort to cover 95 
percent of the U.S. population. The majority of Americans believe that there is a need for reform in the healthcare system and that they are going to have to support specific changes. At the same time, fear of the costs of healthcare reform has been at the center of debates.

There is a strong focus on reducing the costs of drugs and also allowing for the importing of drugs from various countries [44]. Generic drugs will be more readily available and focus on drug company's blocking of such drugs will be addressed [44]. Clearly, Obama's plan was linked to the need to address the profit margin experienced by large pharmaceutical companies while poor and lowincome Americans suffer to obtain basic levels of treatment.

At the same time, it has been recognized that the expense of providing individual insurance coverage for a family can be astronomical. Most middle class families hoping to provide medical coverage for their families face high premium payments or large deductibles that must be met. Though the cost of insurance is often less than the cost of health care services if paid on an individual basis, many families do not have the financial capacity to provide private coverage for their families. If a person in the family has a pre-existing condition, many insurance companies can increase deductibles, increase premiums, or increase co-payments in order to relieve some of their cost in the treatment of the condition. Other insurance companies will chose not to insure the individual with the pre-existing condition, though recent legislation has been designed to relieve this problem. Either way, the message is the same-the health insurance costs in the United States are often prohibitive for middle class families.

It is not surprising that the problems with ethics and the medical decision-making processes of primary care physicians has resulted in the call for government regulation as a proposed component of managed care to ensure the safety of patients as well as physicians against the private companies. But like many other areas of health care reform, the process by which policy makers determine a governmental role for protecting the interests of patients and physicians often is muddled by the personal interests of law makers and lobbyists for large managed care organizations.

\section{Values and politics}

The value-critical framework offered by Chambers and Wedel [43] links the values of individuals and the values of the general public to the process by which change occurs. President Obama identified a group of central points that should be integrated into any program to support expanded healthcare coverage for Americans. He maintained the importance of reducing the ever-increasing cost of health care in this country, with a focus on reducing costs for businesses and government. In addition, President Obama maintained the importance of protecting families who are plagued by debt incurred from expansive health care expenditures, including the fact that many families without insurance go through bankruptcy following long-term illness because of an inability to pay the bills [44].

The healthcare plan identified as an imperative by Obama should also reflect many of the concerns that individuals have voiced about their perceptions of health maintenance organizations, managed care and proposed national health programs: that individuals will not be able to participate in prevention and wellness programming and that individuals will be limited in the selection of physicians and in the type of care they can receive [44]. Critics of national health programs also maintain that measures to introduce government participation often result in declining healthcare quality and safety and this was also introduced as a principle in reform efforts.

To address issues related directly to coverage continuity and affordability, President Obama maintained that healthcare coverage must be affordable for all Americans, should allow for methods to maintain coverage regardless of whether a person is working or unemployed, and should reflect coverage for individuals with preexisting medical conditions [44]. Social values, including those that relate directly to satisfaction and positive outcomes from healthcare change have been introduced as part of the process of introducing substantive change.

Questions of consumer measures of satisfaction and their desire for the program have been introduced as a means of both supporting and denying the need for national interventions. Comparisons have been made with other countries in the industrial world, with the belief that this is the only country where need has been determined. Though the value of national healthcare is recognized in meeting the general needs of society as a whole, there is also information that suggests that other efforts at relating effective health responses, including the protection of universal insurance, has impacted view of national health programs. The values involved in this component of the research reflect the call to provide essential care for the general population while also addressing concerns that include consumer perspectives on obtaining healthcare and methods for funding the program proposed by Obama's team.

Chambers and Wedel's value-committed framework suggests the necessity for activism as a means of supporting the paternalism and call for national interventions in healthcare. The focus on the reform plan was not just to ease the burden of a small population of Americans, but instead to provide affordable health care that is accessible to all Americans and can meet the foundational needs for quality and access to care. There are many roadblocks to true universal care or even to an acceptable level of federal intervention. But, even with his relatively simple changes, in comparison to changes that would occur with universal healthcare, it seems that there will be difficulties. For one thing, the people who make a particular amount of money a year, those making $\$ 250,000$ and over, will not be happy paying higher taxes and the truly rich will likely have influences in industries that will fight against such tax increases.

Some of the central questions raised in the Obama plan include whether or not the health care plan is sustainable over time and if there are actual benefits that can be derived in comparison with the expanded tax responsibilities that will occur as a result of this kind of paternalism. Public polling supports the continued pursuit of this kind of measure, especially in light of the economic losses experienced by the American middle class this past year.

The value committed approach, then, would focus on the necessity for paternalism especially in the time of current economic difficulties. The call for distributive justice, for providing access to care as a component of taxation, even if it means providing additional taxes from the wealthy Americans, is in alignment within the valuecommitted approach to policy making created by Chambers and Wedel [34].

The lack of a viable plan for the funding of the health insurance plan now in the works is clearly at the heart of national debates. Efforts to scale back the program have weakened the arguments in favor of the effort. As a result, there is a need for a reassessment of the progression of information needed to secure support for this program and to 
develop a program that will not fail in the wake of weakened economic conditions.

There are two elements regarding economic changes that must take place in order to secure support for the plan:

1. Economic planning must reflect an awareness of the impacts of changes to the healthcare industry, to large insurance companies, and to the general economy of the country as a whole;

2. Changes in the lost debt, free services and the distribution of money to those who are uninsured now should be evaluated as a potential offset of proposed funding.

Consideration for the potential changes that will occur and planning that is based on assessments of both the immediate costs and the long-term cost savings that can be secured through changes in the structure should be taken into consideration as a component of planning for healthcare reform.

The philosophical and political context in which the healthcare reform measures have been introduced are reflective of a growing dissatisfaction with the cost of medical care and a growing sense of paternalism in government. The Obama plan is based on the belief that the government must take action to support the greatest good for the greatest number of people, and that there can be no assumption that this will happen without government interaction. Though the Republic critics maintain that this is a movement away from the call for decreased government interventions, the supporters of this type of plan, support the use of activism to provide support for the Obama plan. As a country designed to protect the rights of individuals to "life, liberty and the pursuit of happiness" it becomes evident that the level of response and the call for paternalism are directly linked to these aims.

Clearly it is a problem and a problem that has social impacts. When people cannot afford healthcare, and when they fall into a category that does not allow them to be considered poor enough to get a national coverage such as Medicaid, their debt becomes a public debt. When people do not get proper coverage before they are truly ill the costs to the society increase dramatically for when a person finally does get care they are in a serious position.

The impacts of this kind of program should be considered in the development of the plan, especially in light of widespread opposition by existing insurance companies. The insurance companies will do what they can to fight any changes that damage their gains and as is often the case in politics, various legislative plans will be implemented that possess loopholes to protect their interests. Without a degree in economics or at the very least months of intense research, it is impossible to state all the roadblocks that exist when it comes to Obama's plan and the existing legislation that is currently being argued. Though Obama's plan integrates a variety of different elements, a closer scrutiny of the potential benefits and costs of this kind of plan should be secured in order to support the program.

Lasting impacts of this kind of major governmental change should also take into consideration the political and philosophical perspectives that will drive our government in the future. For example, the nature of American paternalism as it exists today must be a consideration in developing strategies for change. If the government is going to focus on this method for structuring government participation this must be a directive for long-term planning. Though there appears to be public support for Obama's paternalism, there are also wealth of critics who may hinder its effectiveness.

\section{The Future of Health Care: a Plausible Plan}

The process of identifying, developing and integrating innovations in governance and public service has been a challenge for leaders and policy makers for decades. One of the most difficult issues that policy makers face is that innovation by its nature is generally perceived as positive, regardless of the nature of the innovation, its purpose or whether the innovation serves an effective purpose. Hartley [45] outlined three specific approaches that have been used to evaluate and integrate innovation in the public sector and essential relates the fact that effective strategies do not start with the assumption that innovation is always necessary or warranted. Just because something is "radical" or "novel" does not define its purpose or justify its utility.

\section{Innovation}

Innovation generally refers to the introduction of new information, of changes from the past ways of doing things that are recognized to correspond with specific issues. For example, the introduction of technology as a communication innovation has been identified through the need for an increase in real-time communications. In governance, innovations are much more complex and relate to a variety of different aspects, from organizational design to the methods through which specific activities are conducted or funded [46]. In efforts to create widespread improvements that have distinct public value in relation to health care, improving service performance in governance has been recognized as a potentially valuable innovation.

Harley [45] divided the concept of innovation into a number of specific areas, which apply to governance and public service innovations within the scope of his research. These innovations include everything from product or service innovations to process innovations, position innovations and innovations that are based in new forms of governance. The most notable changes or innovations often come in the form of service innovations or product innovations that can be viewed immediately. The most difficult to assess and effectively integrate include process innovations, strategic innovations and governance innovations, all of which are impacted by the environment in which they are employed and the connections that are made between organizations involved in different aspects of the invocation [47].

When radical ideas are introduced as a component of the process of innovation, these ideas are impacted by the response to the concept. Hartely [45] argued that just because an idea is novel or radical does not necessarily make the idea a valuable innovation but one of the central problems with innovations is that they are often perceived as beneficial. Radical ideas, then, that does not provide support for the end goals that the organization seeks to secure, must be systematically refuted in order to demonstrate that the innovation is not of value in the existing process. As a result, the justification for the nonacceptance of radical ideas should reflect the goals and desired outcomes of the organizational process and the lack of a correlation between the radical innovation and the end product.

A component of this kind of assessment is the development of a method through which innovations, including incremental innovations over time, can be assessed. Incremental innovations often occur as a component of governance. The concept of decision-making in relation to incremental innovation requires an understanding of the methods for integrating new decisions. The stage-gate system allows of incremental decision-making to correspond with innovations, based on the fact that following each stage in the innovation, a gate, or 
decision-making point occurs. Hartley [45] related a similar process in the connection between innovations and improvements, which allowed for a systematic and tiered approach to evaluating innovation. Innovation should move forwards as improvements increase, and this kind of correlation can be assessed at different points in the process.

Hartley [45] asserted, though, that some organizations can implement changes through an incremental process that does not require the introduction of a major innovation. In other words, improvements can be achieved through the use of a continuous improvement methodology, one that allows for small movements towards an end goal. At the same time, this type of approach may relate a kind of process innovation, one in which change initiatives are created along a continuum that allows for a progression of change, rather than for the introduction of a major shift in process.

Just because some radical ideas do not correspond with the outcomes or expected goals of project does not mean that all radical ideas lack merit. In fact, Hartley argued that essentially the progression of radical ideas is what creates the impetus for change, especially in areas of governance and public service. Hartley recognized, though, that innovations do not always determine improvements in services or process, but sometimes set the foundations for future operations that can realize change [48]. Innovations can be introduced at the same time that other variables also change, creating some question as to the value of innovations.

For example, current public policy moves towards healthcare reform is perceived by many to be a radical innovation that is not necessarily correlated with immediate economic improvements. At the same time, the foundational nature of this radical innovation will serve to develop a culture that provides access to healthcare for all, as a basis for changes that will ultimately positively impact national health and redefine the country's priorities. The immediacy of outcomes in reference to this kind of innovation may be limited, but the potential for long-term change that is incremental and linked to a long-term desired outcome is the underlying purpose and justification for the innovation.

Innovations are not always perceived as beneficial the first time they are introduced. Hartley maintained that in public services, the diffusion of innovations can be difficult to obtain and the success of innovations is often linked to how many people support the innovation. Innovation in governance can be based on the call for change or on a perspective integrated into the process of governance that reflects policy-maker perspectives and changes to improve the way in which organizations realize their end goals [49]. The same innovation may be introduced at different times, with different levels of success. For example, the introduction of the national health program under the Clinton Administration did not receive the kind of support that Obama's current program is gaining, and this relates directly to the framing of the innovation as a part of a public policy initiative. The change initiative and the rhetoric of the innovation were lacking. The end product was a failed attempt at implementing a widespread governance innovation. The reframing of the innovation that occurred in recent years, which changed the methods and the process related to the innovation, defined a greater level of public support for this change.

Hartley's [45] research relates the belief that innovation is a necessary part of public sector organizational change, but it must be related in terms of skeptical view. Hartley identified the fact that the word innovation in itself sometimes sparks an overly positive take on the application. Radical ideas are beneficial in considering the different aspects of governance or organizational process, but innovation is not necessarily in alignment with organizational goals. As a result, innovation must be assessed, defined within the scope of the organization or process, and ultimately related in terms of how it will be implemented and assessed along a continuum.

\section{A Working proposal}

One of the key aspects of a working proposal for health care reform is that stopgap measures for addressing the complexities of the health care industry are likely to result in poor outcomes, especially for vulnerable populations. Obama's proposal, though rejected by many conservatives as hindering private business and lacking costeffectiveness, is one such stopgap measure. In fact, public plans that focus on the balance of public plans and private insurers is much less financially viable than a national health program as a whole [50]. One of the central reasons for this is that some of the basic methods that can be used to obtain funding for a national health program are reliant on the end of private insurance for average health care and the cost savings that can be experienced by individuals and companies that can subsequently be used to fund the program as a whole.

There are elements of Obama's proposal that should be integrated into a new National Health Insurance initiative. These include the following:

\section{Guaranteed eligibility;}

\section{Comprehensive benefits;}

Affordable premiums, co pays or deductibles; and Subsidies [50].

The Baucus Proposal has also been introduced as a means of advancing the Obama plan and creating greater acceptability within the free-market system. This plan would allow for a health insurance exchange that individuals could participate in if they do not have workplace coverage. The exchange would create a new public plan similar to Medicare and would allow for the balancing of goals that include increasing competition and ensuring access to all Americans [50]. Unfortunately, this plan creates another bureaucratic component at a time when existing research suggests that the administrative costs of insurance is one of the factors resulting in inflated costs to the customers.

The development of a plan that can effectively address the needs of the general public while also reducing the administrative costs of health care insurance is clearly a necessity. One of the key aspects of any national health plan is going to have to be the minimization of administrative costs through the focus on state and local government participation in administration. Machikanti and Hirsch [12] reported on a McKinsey Global Institute study that reflected the grow of administrative expenses and the need to control administrative costs as a component of any program development. The McKinsey Global Institute study:

shows that health administration and insurance expense category accounts for $7 \%$ of overall health care costs and $14 \%$ of total spending above expected ( $\$ 91$ billion), spending growing by $6.3 \%$ annually over the 3-year period, resulting in a $\$ 25$ billion increase in costs;

shows that the administrative costs for Medicare enrollee grew by nearly $30 \%$ per year, which largely reflected payouts to private administrators or Medicare advantage plans and the Part D drug 
benefit; shows that from 2005 to 2006 alone, administration for all Medicare programs increased by nearly $\$ 8$ billion [12].

One of the problems in this process, though, is that the industry is currently controlled in many ways by insurance and drug companies, that maintain a high cost, provide significant incentives for continued participation by physicians, and have rallied to defend their freemarket style in Congress. Over the period of time from 2008-2018, researchers have maintained that the spending in health care is expected to increase 6.2 percent a year, leading to an astounding $\$ 4.4$ trillion in health care spending by 2018 [12]. At the same time, growth of the gross domestic product is expected to increase by only 4.1 percent each year, resulting in a much larger percentage of the gross domestic product being paid into the health care industry [12]. Unfortunately, the recent financial crises and the loss of millions of jobs have led to uncertainty in relation to the full impacts on GDP figures. As a result, health-spending projections through 2018 are expected to reach exorbitant levels, while the impacts of the recession suggest declining resources for most American families [12].

The continued operation under the current system, even with reform measures, will result in continued declines in health and a lack of equity in access to health care resources for the poor, the elderly and vulnerable populations. The basis for the free-market approach to health insurance and in the health care industry as a whole is the problematic component of this equation, and Obama's plan does not address the impacts of the free-market approach, which has led to a highly competitive cost structure that is no longer linked to a humanitarian approach to health care.

Manchikanti and Hirsch [12] recognized that the interests of those involved in health care are clearly divergent, and often do not represent the importance of the need of health care to respond to vulnerable populations. Health care reform impacts different groups in different ways, fr3om physicians and providers to employers, insurers, and even politicians and advocacy groups [12]. In fact, some of these groups are going to be negatively impacted by the transition towards any kind of national health care service or nationalized insurance program. One of the misnomers, though, is that the existence of divergent interests means that a program cannot be developed. In fact, legislators have contended that the system based on a free-market approach to insurance is so large and imbedded that is cannot be changed. The United Kingdom, though, demonstrated that efforts can be made towards changes that involve large-scale programming alterations and that successful outcomes can be achieved. In 2008, the United Kingdom introduced new requirements for primary care office practices, and over a 44 month period, transformed the 5,5000 primary care offices serving 32 million individuals towards a prevention strategy in relation to coronary artery disease [12]. Though the transition took time, the belief that collaborative activities can be achieved and improvements implemented across industries is clearly identifiable in relation to health care process.

Reducing costs is an essential part of the health care debate and the only way to bring national interests together. The fact that government administration does not always result in cost containment efforts has been a central criticism in any plan requiring federal administration. As a result, the use of a plan based on state and federal funding mechanisms that would be implemented along the same lines as California's CHIP program and other state-run Medicaid systems would be one element of the plan. In addition to state and local administration, equanimity in participation would be a necessary element, along with the use of state-based methods for negotiating pay-for-service pay scales and for negotiating the regulatory procedures in place at the state level. The following should be goals of the program:

\section{- To provide health care;}

- To completely reform the health care system and end incentives for costly expenditures;

- To reform the market-based insurance system, and push insurers to pursue high-end insurance options for non-covered conditions;

\section{- To reduce administrate waste;}

- To align patient needs with the activities of health care organizations and providers [12].

Some of the elements of the physician plans that have been introduced are valuable when considering an overall plan to meet the needs of the country as a whole. These elements include inclusion provisions; the focus on multiple funding mechanisms on the state and federal level; the use of employer taxation that would meet current levels of health insurance payments; the stipulations regarding administrative process and reimbursement procedures; and the use of technology for the standardization of reporting measures. In addition, methods should be included in the plan for supporting fraud prevention activities in alignment with regulations currently in place under Medicare and Medicaid systems.

The plan funding system could be based on the following components:

\section{- Reductions in Medicare and Medicaid payments;}

- Increasing taxation for employers, who will also experience a cost savings from the end of employer-based insurance programs;

- Reductions in payments to hospitals and providers based on a payfor-service system with costs agreed upon at the state level;

- Decreased expenditures related to the unpaid bills of the uninsured and underinsured;

- Reductions in payments by Medicare and Medicaid for preventable catastrophic illnesses that result from lack of preventative care.

- Reductions in unneeded services resulting from incentive-based payments to hospitals and providers for the use of expensive treatments;

- The increased use of innovations, including technological advancements, which will improve efficiencies, improve the use of electronic medical records, reduce the cost of fraud to the federal government and improve billing and administrative processes.

There are many misconceptions about the uninsured, underinsured and uninsurable in Massachusetts and in the United States as a whole. Many people, who have insurance coverage through their employers, perceive this group as consisting of impoverished families, many of whom are eligible for Medicaid benefits anyway. The reality of the uninsured and uninsurable not represented by Medicaid in the United States is that this population generally consists of middle class families and children. Many of the working adults in the United States can receive health care benefits through their employer. But these benefits often cost employees, who can be required to pay a portion of the premium, and do not necessarily allow for coverage for family members. If a family is already paying $\$ 75$ a month for one member's 
health care coverage, it may not be likely that they can handle the cost of coverage for all of the other family members. This leaves many children without health care coverage, especially in working families that cannot qualify for Medicaid state programs.

Yates [51] stated that the World Health Organization has recognized the need for improvements in health care coverage and has implored countries to implement universal coverage for all citizens as a part of their Millennium Development Goals. In fact, the WHO international panel has maintained the importance of improving health outcomes as a component of addressing international poverty, but has also identified the current health care scenarios in countries like the United States as problematic in relation to poverty [51]. Specifically, the WHO organization has maintained that taking money from poor people who are sick is never a good idea, and those reductions in poverty and improvements in health are linked to the need for an improved health care system in this country [51].

Proposals have reflected the importance of balancing the needs of the most vulnerable populations with an administrative process that places control in the hands of state governments to allocate resources and determine methods for implementing a national health strategy. One of the most difficult components of this process is that large insurers and pharmaceutical companies have invested significantly in the current free-market system, and so will utilize their resources to fight against measures to quell control and replace their functions in the industry. Though this kind of transformation may appear daunting, many countries have implemented national health programs with an existing infrastructure in place, and have been successful at achieving improvements in health care access across populations.

\section{References}

1. Kaiser Family Foundation (2007) Key information on health care costs and their impact.

2. Bartlett D, Steele J (2004) Critical Condition: How Health Care in America Became Big Business and Bad Medicine. DoubleDay, New York.

3. Center on Budget and Policy Priorities (CBPP) (2008) Start healthy, Stay Healthy Campaign.

4. Centers for Disease Control and Prevention (CDC) (2009) Infant mortality rates.

5. Rank MR (2005) One Nation, Underprivileged: why American poverty affects us all. Oxford University Press, New York.

6. (2009) Poverty. National Association of Social Workers (NASW).

7. Blank RM (1997) It takes a nation: A new agenda for fighting poverty. Russell Sage Foundation, New York.

8. Blau J (2005) Mark Robert Rank, one nation underprivileged: why American poverty affects us all. J Sociol Soc Welfare 1: 3 .

9. GovTrac (2009) HR 468.

10. Dawson S, Lundebjerg N (2009) The eldercare workforce alliance urges inclusion of HR 468. Eldercare Workforce Alliance.

11. Berger K (2000) The Developing Person through the Life Span. Palgrave.

12. Manchikanti L, Hirsch J (2009) Health policy: Obama Care for all Americans: Practical implications. Pain Physic 12: 289-304.

13. Lee T, Zapert K (2005) Do high-deductible health plans threaten quality of care? New Eng J Med 353: 1202-1204.

14. Reed M, Fung V, Price M, Brand R, Benedetti N (2009) High-deductible health insurance plans: Efforts to sharpen a blunt instrument. Health Aff 28: 1145-1154.

15. Huskamp H, Deverka P, Epstein A, Epstein R, McGuigan K (2003) The effect of incentive-based formularies on prescription-drug utilization and spending. New Eng J Med 349: 2224-2232.
16. The Massachusetts campaign for single payer health care (2003) Masscare: Why health care for everyone?

17. Andreopoulos S (2007) False promise of state-sponsored health care. San Francisco Chronicle B7.

18. Healthcare for All (2006) SB840. Why is a comprehensive change to our health insurance system needed?

19. Himmelstein D, Warren E, Thorne D (2004) Illness and injury as contributors to bankruptcy. Health Aff 10: 1377.

20. Gorin S, Moniz C (2004) Will the United States ever had universal health care? Health Soc Work 29: 340-344.

21. Frist W (2005) Overcoming disparities In US health care. Health Aff 24: 445-450.

22. Duncan D, Quarells R, Jones D (2005) Approaching health equity. J Nati Med Assoc 97: 584-585.

23. Shi Leiyu, Singh Douglas A (1998) Delivering health care in America: A systems approach. Aspen Publishers, Gaithersburg Md: 8-98.

24. Miller W, Vigdor E, Manning W (2004) Covering the uninsured: what is it worth? Health Aff 4: 157-167.

25. Reynolds William A (1997) Health care reform: how bright prospects plummeted. ACP Observer.

26. Palmer Karen L (1999) A brief history: Universal health care efforts in the U.S. late 1800 's to medicare.

27. The Commonwealth Of Massachusetts (2008) An act making appropriations for fiscal year 2009.

28. (2007) Wisconsin reveals the cost of "universal" health care. The Wall Street Journal.

29. Benison Martin J (2006) Comprehensive annual financial report for the fiscal year ended June 30, 2006. Commonwealth of Massachusetts.

30. Beacon Hill Institute (2007) Massachusetts tax revenue forecasts for FY 2007 and FY 2008. Beacon Hill Institute at Suffolk University.

31. California Health Advocates (2009) Overview of Medicare Advantage Plans.

32. State Health Facts (2009) Children's Medicaid and CHIP Eligibility.

33. State of California (2007) Medi-Cal. Department of Health Care Services.

34. (2009) Kaiser State Health Facts.

35. Healthy Families (2009) affordable health care for children.

36. Davis K, Schoen C, Schoenbaum S, Doty M, Holmgren A (2007) Mirror, mirror on the wall: An international update on the comparative performance of American health care.

37. Himmelstein D,Woolhandler S (1989) A National Health Program for the United States: A Physicians' Proposal. New Eng J Med 320: 102-108.

38. (2003) Proposal of the physicians' working group for single-payer national health insurance. JAMA 290: 798-805.

39. HR 3590 (2009)

40. American Medical Association (2009) Health Systems reform: Legislative summary chart of major provisions.

41. Health Care and Education Affordability Act of 2010.

42. Obama B (2004) Keynote speech at the democratic national convention. American Rhetoric

43. Chambers DE, Wedel K (2005) Social policy and social programs: A method for the practical public policy analyst. Allyn and Bacon, Boston.

44. Obama B (2009) Principles for Health Reform.

45. Hartley J (2005) Innovation in governance and public services: Past and present. Pub Money Managem 27-34.

46. Borins S (2001) The Challenge of innovating in government. Arlington, VA: Price waterhouse Coopers Endowment for the Business of Government.

47. Newman J, Raine J, Skelcher C (2000) Innovation in local government: A Good Practice Guide. DETR, London.

48. Hartley J, Allison M (2002) Good, better, best? Inter-organizational learning in a network of local authorities. Pub Manag Rev 4: 101-118. 
Citation: Boudreau R (2017) The Plausibility of Universal Health Care in the United States. J Clin Res Bioeth 8: 1000298. doi: 10.4172/2155-9627.1000298

Page 21 of 21

49. Hacker J (2009) The case for public plan choice in national health reform: Key to cost control and quality coverage.

50. Yates R (2009) Viewpoint. The Lancet 373: 2078-2081.
51. Armas G (2011) People 65-plus increase by $300 \% .420$ million seniors worldwide retire earlier, live longer. Associated Press. 